\title{
Article
}

\section{Seismic Performance of Grille-Type Steel Plate Concrete Composite Walls with Application in a Super-High-Rise Building}

\author{
Yang Liu ${ }^{1}$, Hao $\mathrm{Wu}^{2, *}$,, Qiao $\mathrm{Yu}^{2}$, Yun $\mathrm{Li}^{1}{ }^{1},{\mathrm{Jianan} \mathrm{Li}^{1}}^{1}$ and Lingzhi $\mathrm{Li}^{2}$ \\ 1 China Construction Seventh Engineering Division (Shanghai) Corp., Ltd., 235 E. Yunling Rd., Putuo District, \\ Shanghai 200062, China; liuyang10@cscec.com (Y.L.); liyun921102@outlook.com (Y.L.); liy15@cscec.com (J.L.) \\ 2 Department of Disaster Mitigation for Structures, College of Civil Engineering, Tongji University, \\ 1239 Siping Rd., Shanghai 200092, China; yq_@tongi.edu.cn (Q.Y.); lilingzhi@tongii.edu.cn (L.L.) \\ * Correspondence: 2009wuhao_tom@tongji.edu.cn
}

check for updates

Citation: Liu, Y.; Wu, H.; Yu, Q.; Li, Y.; Li, J.; Li, L. Seismic Performance of Grille-Type Steel Plate Concrete Composite Walls with Application in a Super-High-Rise Building. Appl. Sci. 2021, 11, 7580. https://doi.org/ 10.3390/app11167580

Academic Editors: Kang Su Kim, Myoungsu (James) Shin, Kil-Hee Kim and Jong Wan $\mathrm{Hu}$

Received: 31 May 2021

Accepted: 16 August 2021

Published: 18 August 2021

Publisher's Note: MDPI stays neutral with regard to jurisdictional claims in published maps and institutional affiliations.

Copyright: (c) 2021 by the authors. Licensee MDPI, Basel, Switzerland. This article is an open access article distributed under the terms and conditions of the Creative Commons Attribution (CC BY) license (https:/ / creativecommons.org/licenses/by/ $4.0 /)$.
Featured Application: The grille-type steel plate concrete composite wall (GSPCW) is an innovative shear wall system that has recently been developed. This type of shear wall is characterized by large vertical and lateral load capacity while maintaining large deformation capability. Since barely any traditional reinforcing bars are needed, the structural measures for wall construction are simple and can be easily implemented. Based on both experimental and numerical investigations of the GSPCW wall components, the seismic performance of GSPCW walls have been verified to be satisfactory in terms of load-bearing capacity, stiffness and deformation capacity, energy dissipation, etc. Moreover, further analysis on the application of GSPCW walls in a superhigh-rise building as a case study show the excellent performance of the system. Based on these findings, it can be inferred that GSPCW wall could be used as an alternative system for conventional steel concrete composite wall, and is expected to be a promising system for high-rise buildings in seismic regions.

Abstract: The grille-type steel plate concrete composite wall (GSPCW) is an innovative shear wall system that mainly consists of steel faceplates, steel tie plates and infilled concrete. Compared to traditional steel plate concrete composite shear walls, the advantages of GSPCW walls include: (1) relatively high lateral and buckling resistance; and (2) simple structural measures for convenient construction and implementation. This paper presents the results of extensive numerical investigations regarding GSPCW systems, examining both GSPCW wall components and their application in a super-high-rise building as a case study. First, typical GSPCW wall models are established using DIANA software, and the numerical models are validated on the basis of comparison with results from previously reported experimental tests. The verified models are further used to perform parametric analyses with the aim of further understanding the effects of various design parameters on the seismic performance of GSPCW systems, including steel ratio, axial load ratio, height-to-width ratio, aspect ratio of the grille steel plate, and concrete compressive strength. Second, a super-high-rise building was selected for application to perform a case study of a GSPCW system. The seismic performance of the tall building in the case study was comparatively evaluated on the basis of both nonlinear time history analysis and modal pushover analysis (MPA), and the results from both of these methods validated the use of GSPCW is an efficient structural wall system appropriate for use in super-high-rise buildings. Finally, a simple economic assessment of the GSPCW building was performed, and the results were compared with those obtained for conventional reinforced concrete wall buildings.

Keywords: steel concrete composite wall; grille-type steel plate; modal pushover analysis; seismic performance assessment; super-high-rise building 


\section{Introduction}

Steel plate concrete shear wall is a composite structural wall system that is formed by placing steel plates on one or both sides of a concrete slab or inside a concrete core. The steel and concrete are typically combined using shear nails or bolt tie rods on steel plate. Depending on the layout of the steel plate, such composite shear wall systems can be classified into three main categories, i.e., single-sided, double-sided, and embedded steel plate concrete composite shear walls [1]. A large amount of research has been performed on various types of steel plate concrete composites. On the basis on previous research, steel plate concrete composite shear walls normally possess high load resistance, high stiffness, and excellent ductility and energy dissipation capacity [2-5].

Despite their excellent performance, traditional steel plate concrete composite shear walls may experience buckling failure of the steel plate, which affects the overall seismic behavior of the system. Furthermore, conventional steel plate concrete composite walls may also require some reinforcing bars when used in the design of wall sections. To improve the performance of existing plate concrete composite shear walls, $\mathrm{Xu}$ et al. [6] proposed an innovative grille-type steel plate concrete composite shear wall (GSPCW). As shown in Figure 1, GSPCW is consists primarily of steel faceplates, steel tie plates and infilled concrete, and steel channels are normally placed at the wall ends. The grille-type steel plates are arranged so as to improve the buckling capacity of the steel plate, while maintaining the advantages of conventional steel plate concrete composite shear wall systems.

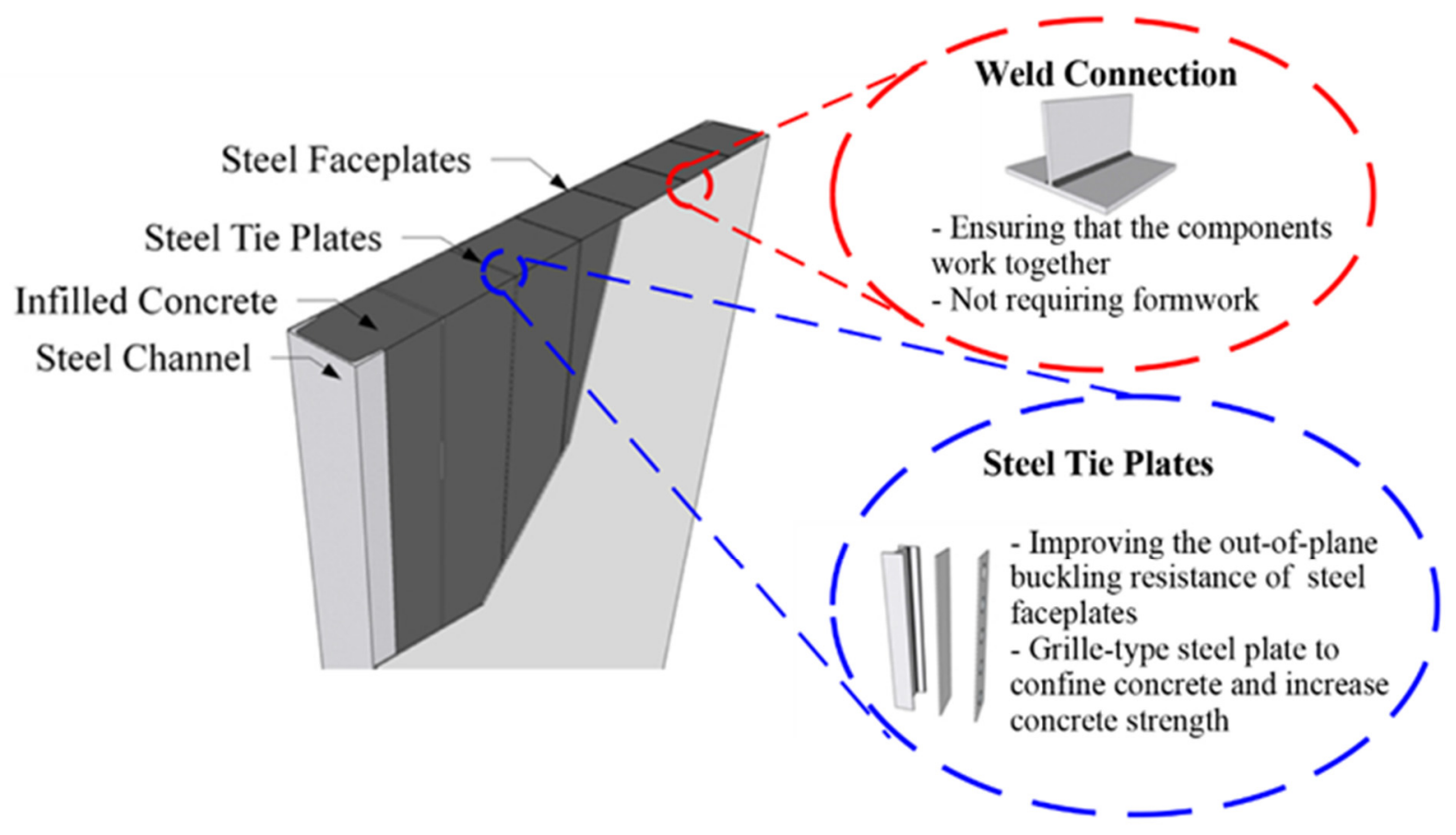

Figure 1. Schematic of grille-type steel plate concrete composite shear walls (GSPCWs).

To date, only limited research has been performed regarding GSPCW wall systems. This research was initiated by Guo et al. [7], and was focused on analyzing the effects of different design parameters on the seismic behavior of GSPCW with embedded corrugated steel plate on the basis of laboratory testing and numerical simulations. The results indicated that the out-of-plane deformation of steel plates on both sides of the shear wall were effectively constrained due to the concrete slab and the corrugated steel tie plates, thereby significantly improving the out-of-plane buckling resistance of the steel plates. $\mathrm{Xu}$ et al. [8] and Ye et al. [9] further improved the structure of GSPCW systems and replaced the embedded corrugated steel plates with single independent steel plates. Zhang et al. [10] 
recently conducted seismic performance tests on three GSPCW walls. The results of their study demonstrated that the improved GSPCW shear wall system exhibited good seismic performance.

This paper aims to further evaluate the effects of various design parameters on the seismic behavior of GSPCW walls, as well as its application in engineering practice. First, a two-dimensional numerical model for GSPCW walls is established using DIANA software based on the test specimens from Ye et al. [9]. A total of eighteen GSPCW wall models with varying design parameters are established to systematically to investigate the effects of different design parameters, including steel ratio, axial load ratio, height-width ratio, aspect ratio of the grille, and concrete compressive strength. The conclusions from the parametric analyses can act as a reference for engineering practice. Second, a super-high-rise building is selected as a case study with the use of GSPCW for the core walls of the structure. The seismic performance of the analytical structure is analyzed using both nonlinear time history analysis (NTHA) and modal pushover analysis (MPA), and the results obtained using these two distinct methods are compared to evaluate the potential capability for application of GSPCW walls in super-high-rise buildings. Finally, a simple economic assessment of the GSPCW building is performed in comparison with conventionally reinforced concrete wall buildings.

\section{Numerical Modeling and Validation}

\subsection{Literature Tests for GSPCW Walls}

As mentioned earlier, very limited experimental research related to GSPCW wall system has been performed to date. Therefore, the two GSPCW wall specimens tested by Ye et al. [9] were selected in the study and used for numerical modeling verification. Figure 2 shows the schematic for and photo of the test walls, and the design details of the specimens are listed in Table 1. As shown, the two selected wall specimens have almost the same design parameters, except for the axial load ratio, which is the main variable of concern in the tests. The concrete grade is C40, and the steel grade is Q235B, based on the Chinese design code. Since the loading beam and the foundation beam are made of reinforced concrete, the steel beam of the $\mathrm{H}$ section is embedded in order to improve the stiffness of the foundation beam. More details relating to the two wall specimens can be found in Ye. [9].

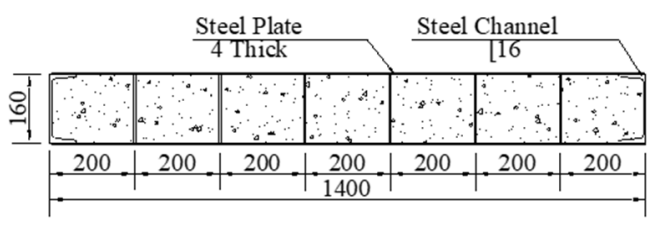

(a)

Figure 2. Cont. 


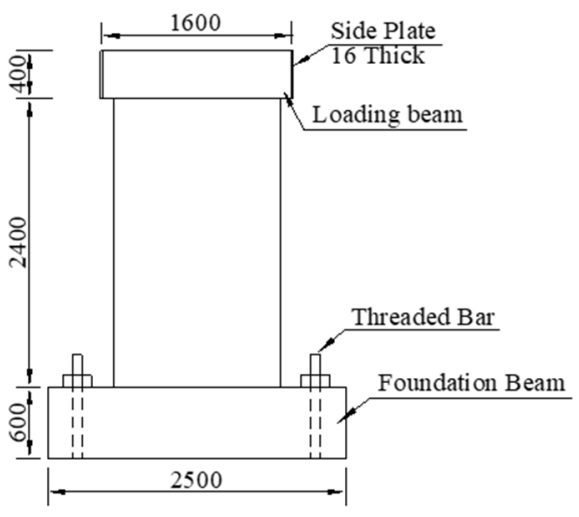

(b)

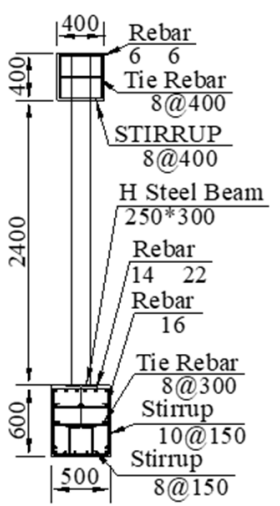

(c)

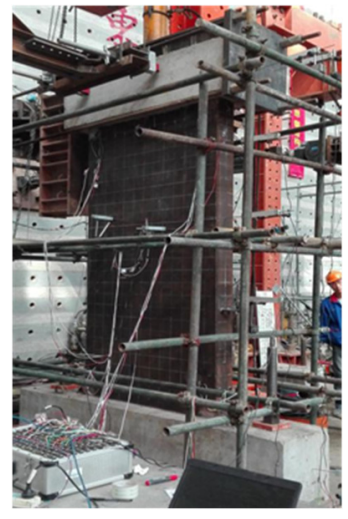

(d)

Figure 2. Tested GSPCW walls (adapted from [9]): (a) cross-section; (b) front view; (c) side view; (d) photo.

Table 1. Design parameters for the wall specimens [9].

\begin{tabular}{ccccccc}
\hline Wall ID & $\begin{array}{c}\text { Wall Dimension } \\
\mathbf{W} \times \mathbf{T} \\
(\mathbf{m m} \times \mathbf{m m})\end{array}$ & $\begin{array}{c}\text { Steel Plate } \\
\text { Thickness } \\
(\mathbf{m m})\end{array}$ & $\begin{array}{c}\text { Steel Channel } \\
(\mathbf{m m} \times \mathbf{m m} \times \mathbf{m m})\end{array}$ & $\begin{array}{c}\text { Axial Load } \\
\text { Ratio }\end{array}$ & $\begin{array}{c}\text { Concrete } \\
\text { Strength } \\
\mathbf{( M P a})\end{array}$ & $\begin{array}{c}\text { Steel Plate } \\
\text { Strength } \\
\mathbf{( M P a})\end{array}$ \\
\hline GSPCW-1 & $1400 \times 160$ & 4 & {$[16(160 \times 64 \times 5)$} & 0.1 & 26.6 & 263.2 \\
GSPCW-2 & $1400 \times 160$ & 4 & {$[16(160 \times 64 \times 5)$} & 0.4 & 26.6 & 263.2 \\
\hline
\end{tabular}

Note: ${ }^{*} \mathrm{~W}$ is wall width, and $\mathrm{T}$ is wall thickness.

The test setup of the wall specimens consisted of a bottom fixing device, out-of-plane supports, and vertical and lateral loading devices. The lateral loading protocol adopted both force control and displacement control loading protocols. The vertical load was applied using a hydraulic jack, and a steel beam was placed on the top of the loading beam in order to distribute the vertical loads in an averaged fashion. Before the application of formal lateral loading, lateral preloading was carried out to make sure that all the loading equipment, connectors, data acquisition system were in good condition. After that, a single-stage lateral load using load control protocol was applied until the specimen yielded. Once the specimen had yielded, displacement control multi-stage loading were applied until the lateral capacity of the specimen reached its peak, and then decreased to $85 \%$ of the load capacity, indicating failure.

\subsection{Numerical Models}

\subsubsection{Modeling Assumptions}

Since the test walls were in-plane loaded and constrained in the out-of-plane direction during testing, a two-dimensional simulation scheme was deemed to be sufficient, and was subsequently adopted for the modeling in this study. Figure 3 shows the schematic of the GSPCW wall models developed in DIANA software [11]. As shown, an eight-node quadrilateral isoparametric plane stress element was used to model the infill concrete, steel faceplates, loading beam and foundation beam. A bar reinforcement element was used for the steel tie plates. No consideration for the interface between concrete and steel plates was modeled, since no data on this have been reported for test wall specimens. The mesh size for all of the elements was $50 \mathrm{~mm}$, and the translation of the bottom of the foundation beam was constrained. The FE models were loaded in two steps following the same protocol as in the tests: the vertical loading was applied first to the top of the loading beam at uniform pressure, and then cyclic lateral displacement-controlled loading was applied to the centroid of the loading beam. The modified Newton-Raphson method was used for the incremental iterative solution. The convergence criteria combine both force norm and displacement norm. In addition, geometrical nonlinearity was considered in the analysis. 


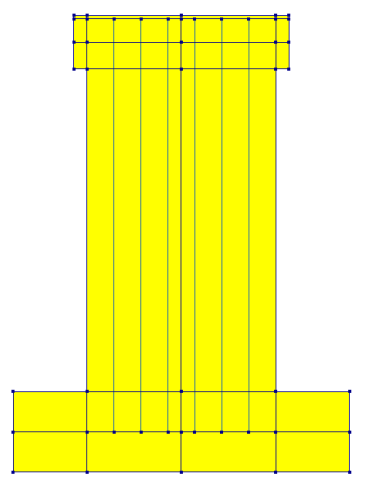

(a)

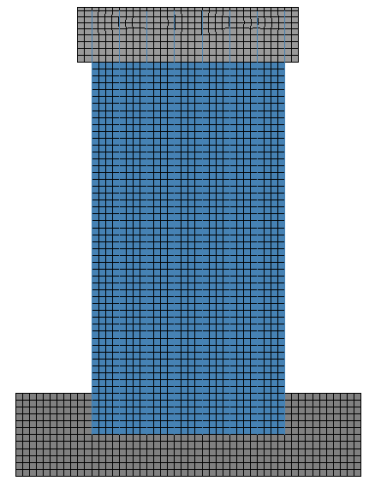

(b)

Figure 3. GSPCW wall models in DIANA: (a) model schematic; (b) meshed model with loading conditions and constraints.

\subsubsection{Material Models}

The material model for the infilled concrete in GSPCW walls was selected as the total strain crack model in DIANA. The input parameters for this concrete model include the elastic concrete properties, cracking direction, and uniaxial behavior of concrete under compression and tension. The secant unloading method was used for total strain crack model and the internal damage variables $\alpha_{k}$ were used to monitor the strain of the concrete due to cracking and crushing, which is related to the constitutive model of concrete, see Figure 4. The cracking direction was selected as the rotating direction, and the shear stiffness remained constant. Figure 4 also shows the stress-strain constitutive relationship for the uniaxial behavior of concrete. In this study, the model proposed by Mander et al. [12] was adopted as the constitutive model of concrete under compression, and is applicable to concrete constrained by both circular- and rectangular-shaped reinforcement. The constraint effects of the steel plates on concrete can be regarded as a constraint effect with many transverse reinforcements on concrete, as in the following formula:

$$
\begin{gathered}
f_{c}=\frac{f_{c c}^{\prime} x r}{r-1+x^{r}} \\
x=\frac{\varepsilon_{c}}{\varepsilon_{c c}} \\
\varepsilon_{c c}=\varepsilon_{c o}\left[1+5\left(\frac{f_{c c}^{\prime}}{f_{c o}^{\prime}}-1\right)\right] \\
r=\frac{E_{C}}{E_{C}-E_{\mathrm{sec}}} \\
E_{\mathrm{sec}}=\frac{f_{c c}^{\prime}}{\varepsilon_{c c}}
\end{gathered}
$$

where $f_{c c}^{\prime}$ is the compressive strength of confined concrete, $\varepsilon_{c}$ is the longitudinal compressive concrete strain, $f_{c o}^{\prime}$ is the unconfined concrete strength and $\varepsilon_{c o}^{\prime}$ is the corresponding strain, which can be assumed to be 0.002 . $E_{c}$ is the elastic modulus of concrete, which can be calculated using $E_{c}=5000 \sqrt{f_{c c}^{\prime}}$. The compressive strength of confined concrete $f_{c c}^{\prime}$ can be determined by the confinement effectiveness of steel plates and calculated as described by Cai et al. [13]. The constitutive model of concrete under tension was calculated according to CEB-FIP Model 1990 [14], and the formula is given by:

$$
f_{t}= \begin{cases}0.26 f_{c u}^{2 / 3} & \left(f_{c u} \leq 50 \mathrm{MPa}\right) \\ 0.21 f_{c u}^{2 / 3} & \left(f_{c u}>50 \mathrm{MPa}\right)\end{cases}
$$




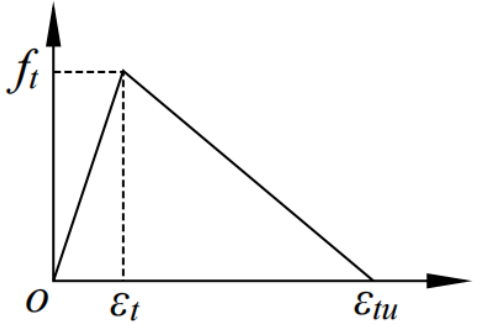

(a)

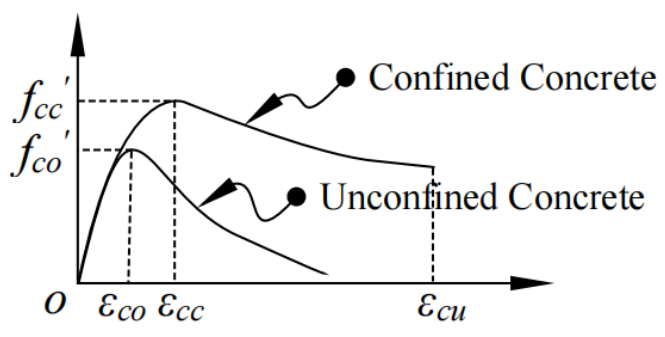

(b)

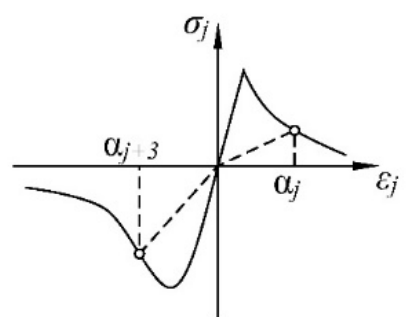

(c)

Figure 4. The constitutive relationship of concrete: (a) tension; (b) compression; (c) loading-unloading protocol.

The constitutive model for steel in the study adopts a simple bilinear elastic hardening material model. The elastic modulus, yielding strength, and ultimate strength were all based on material properties determined by tests in Ref. [9]. The Von Mises yielding criterion was selected to describe the yielding status of steel.

\subsection{Validation of Numerical Modeling}

Figure 5 compares the results from numerical models with experimental results for the test walls described in Section 2.1 in terms of load-displacement hysteresis curves and secant stiffness degradation curves. It can be seen from the figure that the hysteresis curves obtained from the numerical simulation are in good agreement with the test results for both of the selected wall specimens. The magnitude of the peak load, the initial stiffness, and the hysteresis energy dissipation are all reasonably matched with the test results. Secant stiffness degradation can be calculated on the basis of the hysteresis curves, and it also shows good agreement between the simulation and the experimental results. Please note that Table 2 lists all of the values of force and displacement corresponding to the characteristic points for both the simulation and the experimental results in the skeleton curves (in both positive and negative directions). These characteristic points include yielding point, peak capacity point and ultimate capacity point.

Table 2. Comparison of characteristic points of skeleton curves.

\begin{tabular}{|c|c|c|c|c|c|c|c|}
\hline Wall ID & & $\begin{array}{c}\text { Loading } \\
\text { Direction }\end{array}$ & $\begin{array}{c}F_{\mathbf{y}} \\
(\mathbf{k N})\end{array}$ & $\begin{array}{c}D_{y} \\
(\mathrm{~mm})\end{array}$ & $\begin{array}{c}F_{\mathrm{p}} \\
(\mathbf{k N})\end{array}$ & $\underset{(\mathrm{mm})}{D_{\mathrm{p}}}$ & $\begin{array}{c}D_{\mathrm{u}} \\
(\mathrm{mm})\end{array}$ \\
\hline \multirow{4}{*}{ GSPCW-1 } & \multirow{2}{*}{ Test } & positive & 803.47 & 10.94 & 1079.54 & 52.90 & 92.60 \\
\hline & & negative & 840.59 & 13.10 & 930.00 & 55.40 & 91.90 \\
\hline & \multirow{2}{*}{ Model } & positive & 898.69 & 7.75 & 1078.70 & 20.00 & 75.57 \\
\hline & & negative & 890.34 & 7.52 & 1060.00 & 20.00 & 91.00 \\
\hline \multirow{4}{*}{ GSPCW-2 } & \multirow{2}{*}{ Test } & positive & 931.24 & 4.81 & 1223.11 & 26.64 & 66.80 \\
\hline & & negative & 885.27 & 7.55 & 1070.00 & 26.40 & 60.04 \\
\hline & \multirow[b]{2}{*}{ Model } & positive & 1019.34 & 7.92 & 1190.00 & 13.00 & 40.07 \\
\hline & & negative & 1002.53 & 7.90 & 1180.00 & 14.00 & 35.73 \\
\hline
\end{tabular}

Notes: $\boldsymbol{F}_{\mathbf{y}}$ and $\boldsymbol{F}_{\mathrm{p}}$ are the lateral force capacity of specimens at the yield and peak point, respectively; $\boldsymbol{D}_{\mathbf{y}}, \boldsymbol{D}_{\mathbf{p}}$ and $\boldsymbol{D}_{\mathbf{u}}$ are the lateral displacement at the loading point of the specimens at the yield point, peak point and ultimate point, respectively; and the ultimate point is the point at which the bearing capacity decreases to $85 \%$ that of the peak point. 


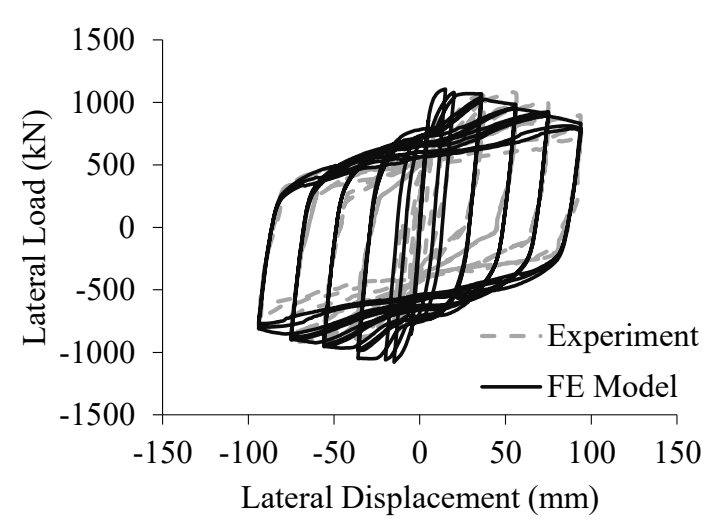

(a)

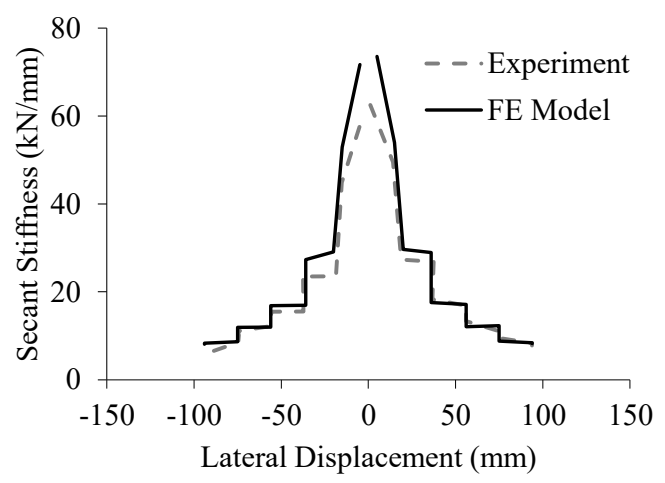

(c)

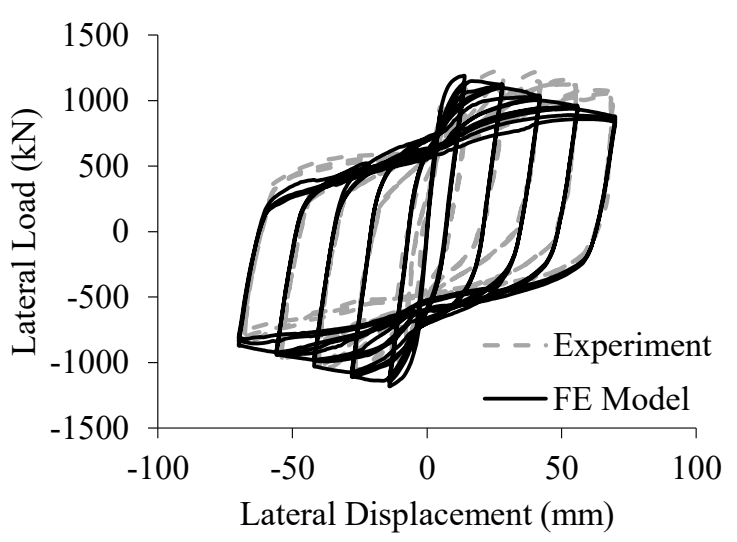

(b)

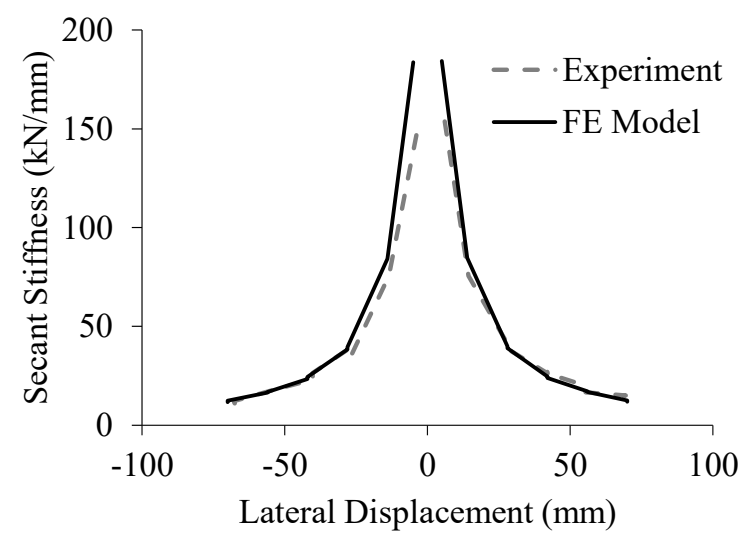

(d)

Figure 5. Comparison of experimental and simulation results: load-displacement hysteresis curves of specimen (a) GSPCW1 and (b) GSPCW-2; secant stiffness degradation of specimen (c) GSPCW-1 and (d) GSPCW-2.

\section{Parametric Modeling of GSPCW Walls}

To extend our understanding of GSPCW wall systems beyond the limited test data, parametric modeling of GSPCW walls based on test walls was performed. In this study, a total of 18 wall models with varying design parameters were simulated. Table 3 lists all of the variations of the parametric wall models. These parameters include: (1) Steel ratio, defined as the ratio of the total steel area to the gross wall section area. Note that the variations in steel ratio are achieved by varying the thickness of the steel faceplates and the steel tie plates; (2) Axial load ratio, defined as the ratio of total vertical load to the product of concrete compressive strength and the wall gross section area; (3) Height-towidth ratio, defined as the ratio of the wall height to the wall section width; (4) Aspect ratio of the grille-type steel, defined as the ratio of the spacing of the steel tie plates to the thickness of the wall section; and (5) Concrete compressive strength. In the process of parametric analysis, the values for material strength were taken from the Chinese Code for Design of Concrete Structures (GB50010-2010) [15] and Code for Design of Steel Structures (GB50017-2017) [16]. 
Table 3. Parameter variations for numerical parametric analyses.

\begin{tabular}{|c|c|c|c|c|c|c|c|c|}
\hline Wall ID & $\begin{array}{c}\text { Wall Dimension } \\
\mathbf{W} \times \mathrm{T}^{*} \\
(\mathrm{~mm} \times \mathbf{m m})\end{array}$ & $\begin{array}{l}\text { Height } \\
(\mathrm{mm})\end{array}$ & $\begin{array}{l}\text { Height-to- } \\
\text { Width } \\
\text { Ratio }\end{array}$ & $\begin{array}{c}\text { Concrete } \\
\text { Grade }\end{array}$ & $\begin{array}{l}\text { Aspect Ratio } \\
\text { of Grille } \\
\text { Steel Plate }\end{array}$ & $\begin{array}{c}\text { Axial Load } \\
\text { Ratio }\end{array}$ & $\begin{array}{l}\text { Steel Plate } \\
\text { Thickness }\end{array}$ & Steel Ratio \\
\hline GSPCW1-1 & $1400 \times 160$ & 2800 & 2.0 & C40 & 1.25 & 0.3 & 3 & $7.2 \%$ \\
\hline GSPCW1-2 & $1400 \times 160$ & 2800 & 2.0 & C40 & 1.25 & 0.3 & 4 & $8.9 \%$ \\
\hline GSPCW1-3 & $1400 \times 160$ & 2800 & 2.0 & C40 & 1.25 & 0.3 & 5 & $10.5 \%$ \\
\hline GSPCW1-4 & $1400 \times 160$ & 2800 & 2.0 & $\mathrm{C} 40$ & 1.25 & 0.3 & 6 & $12.1 \%$ \\
\hline GSPCW2-1 & & \multicolumn{7}{|c|}{ same as GSPCW1-2 } \\
\hline GSPCW2-2 & $1400 \times 160$ & 2800 & 2.0 & C40 & 1.25 & 0.4 & 4 & $8.9 \%$ \\
\hline GSPCW2-3 & $1400 \times 160$ & 2800 & 2.0 & $\mathrm{C} 40$ & 1.25 & 0.5 & 4 & $8.9 \%$ \\
\hline GSPCW2-4 & $1400 \times 160$ & 2800 & 2.0 & C40 & 1.25 & 0.6 & 4 & $8.9 \%$ \\
\hline GSPCW2-5 & $1400 \times 160$ & 2800 & 2.0 & $\mathrm{C} 40$ & 1.25 & 0.7 & 4 & $8.9 \%$ \\
\hline GSPCW3-1 & $1400 \times 160$ & 2100 & 1.5 & C40 & 1.25 & 0.3 & 4 & $8.9 \%$ \\
\hline GSPCW3-2 & & \multicolumn{7}{|c|}{ same as GSPCW1-2 } \\
\hline GSPCW3-3 & $1400 \times 160$ & 3500 & 2.5 & C40 & 1.25 & 0.3 & 4 & $8.9 \%$ \\
\hline GSPCW3-4 & $1400 \times 160$ & 4200 & 3.0 & C40 & 1.25 & 0.3 & 4 & $8.9 \%$ \\
\hline GSPCW3-5 & $1400 \times 160$ & 4900 & 3.5 & $\mathrm{C} 40$ & 1.25 & 0.3 & 4 & $8.9 \%$ \\
\hline GSPCW4-1 & $1400 \times 160$ & 2800 & 2.0 & C40 & 1.75 & 0.3 & 4 & $8.3 \%$ \\
\hline GSPCW4-2 & $1400 \times 160$ & 2800 & 2.0 & $\mathrm{C} 40$ & 1.46 & 0.3 & 4 & $8.6 \%$ \\
\hline GSPCW4-3 & & \multicolumn{7}{|c|}{ same as GSPCW1-2 } \\
\hline GSPCW4-4 & $1400 \times 160$ & 2800 & 2.0 & C40 & 1.09 & 0.3 & 4 & $9.1 \%$ \\
\hline $\begin{array}{l}\text { GSPCW5-1 } \\
\text { GSPCW5-2 }\end{array}$ & $1400 \times 160$ & 2800 & 2.0 & C30 & $\begin{array}{c}1.25 \\
\text { same as GSPCh }\end{array}$ & 0.3 & 4 & $8.9 \%$ \\
\hline $\begin{array}{l}\text { GSPCW5-2 } \\
\text { GSPCW5-3 }\end{array}$ & $1400 \times 160$ & 2800 & 2.0 & C50 & 1.25 & 0.3 & 4 & $8.9 \%$ \\
\hline GSPCW5-4 & $1400 \times 160$ & 2800 & 2.0 & C60 & 1.25 & 0.3 & 4 & $8.9 \%$ \\
\hline
\end{tabular}

Note: ${ }^{*} \mathrm{~W}$ is wall width, and $\mathrm{T}$ is wall thickness.

\subsection{Steel Ratio}

As demonstrated in Table 3, changes in steel ratio can be accomplished by varying the thickness of the steel plate, i.e., thicker steel plate leads to a higher steel ratio. Figure 6 shows the hysteresis and skeleton curves for the parametric wall models with different steel ratios. It can be observed from the figure that with increasing steel ratio, there is an increase in loading capacity and post-yielding stiffness of the model walls. Because the axial load ratio of the models is relatively low (i.e., 0.3), the stiffness of the specimen is basically determined by the elastic stiffness of the cross-section, will the infill concrete accounting for a large part of this contribution to stiffness. Therefore, the increase in post-yield stiffness is relatively smaller than the increase in load capacity.

$$
\rho_{s}=\frac{A_{s}}{A}
$$

where $\rho_{s}$ is the steel ratio, $A_{s}$ is the horizontal cross-section area of the steel, and $A$ is the entire horizontal cross-section. 


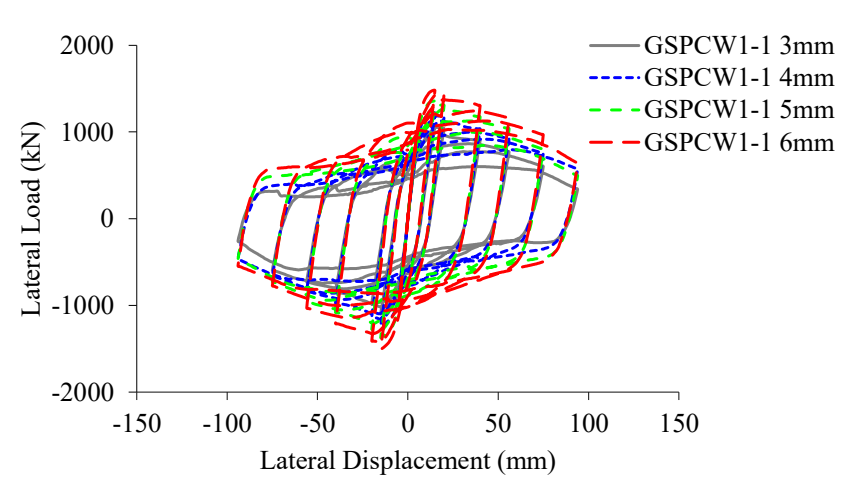

(a)

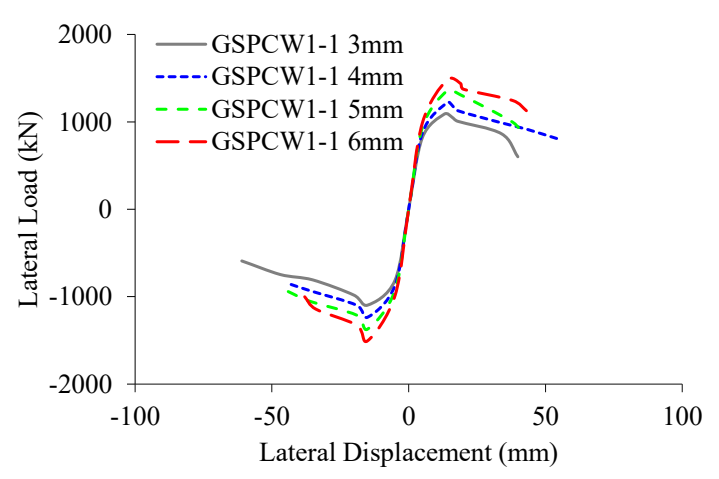

(b)

Figure 6. Influence of steel ratio: (a) load-displacement hysteresis curves, and (b) skeleton curves.

\subsection{Axial Load Ratio}

The axial load ratio is was varied between 0.3 and 0.7 . Figure 7 shows the hysteresis and skeleton curves for the parametric wall models with different axial load ratios. It can be seen from the figure that the lateral load capacity calculated by numerical modeling varies little, but the ductility for the GSPCW walls exhibits some changes influenced by variations in the axial load ratio, i.e., as the axial load ratio increases, the ductility decreases. As can be seen from the figure, when the axial load ratio is greater than 0.5 , the ductility appears to evidently decrease as compared with axial load ratios below 0.5 . Consequently, it is recommended in this study that the axial load ratio of GSPCW walls be controlled to below 0.5 in practice in order to ensure good ductility performance.

$$
n=\frac{N}{f_{c}^{\prime} A}
$$

where, $n$ is axial load ratio, $N$ is the vertical compressive force, $f_{c}^{\prime}$ is the compressive strength of concrete, $A$ is the entire horizontal cross-section.

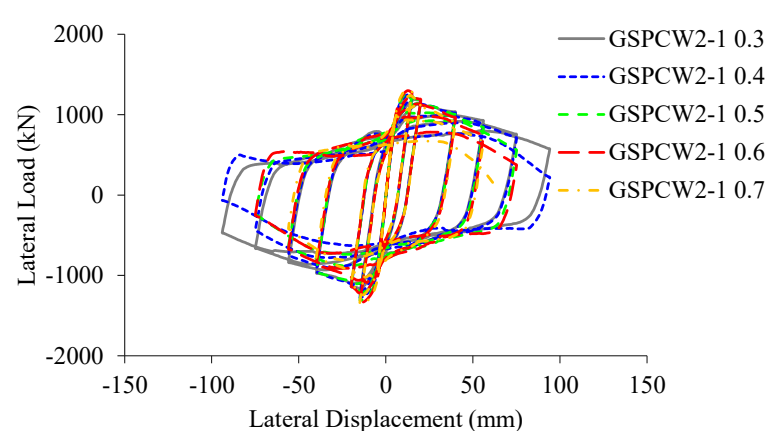

(a)

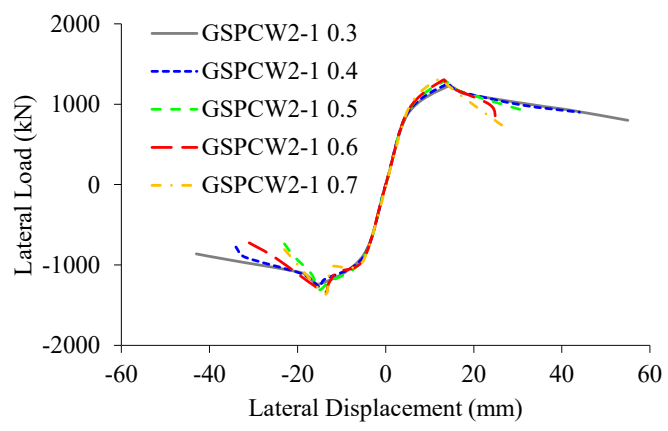

(b)

Figure 7. Influence of axial load ratio: (a) load-displacement hysteresis curves, and (b) skeleton curves.

\subsection{Height-to-Width Ratio}

The height-to-width ratio is one of the main factors that determines the failure type of shear walls and affects their seismic performance. The height-to-width ratios of the model studied in this paper were selected in the range from 1.5 to 3.5, as listed in Table 3, thus being representative of common height-to-width ratio values in engineering practice for shear walls. Figure 8 shows the hysteresis and skeleton curves for the parametric wall models with different height-to-width ratios. It can be seen from the figure that the height-to-width ratio has a distinct effect on the load capacity and stiffness of the wall 
models. As the height-to-width ratio increases from 1.5 to 3.5 , the load capacity decreases by $59 \%$, and its lateral stiffness decreases by $88 \%$. This is because as the height-to-width ratio increases, the failure mode of the specimen transfers from shear failure to bending failure.

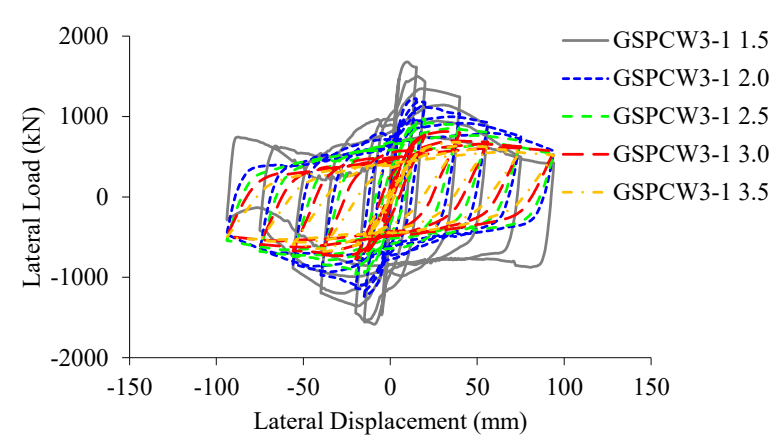

(a)

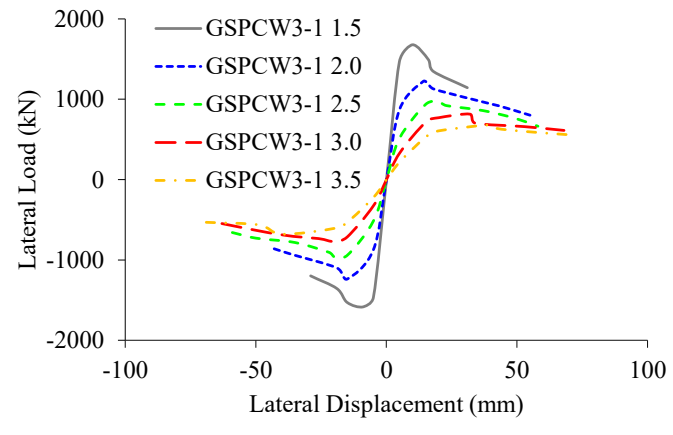

(b)

Figure 8. Influence of the height-to-width ratio: (a) load-displacement hysteresis curves, and (b) skeleton curves.

\subsection{Aspect Ratio of Grille-Type Steel Plate}

Figure 9 shows the hysteresis and skeleton curves for the parametric wall models for grille-type steel plates with different aspect ratios. It can be seen from the figure that the aspect ratio of the grille only influences the lateral behavior of GSPCW walls to a certain extent. As the aspect ratio of the grille decreases, the lateral load capacity of the wall model increases. This is because the steel faceplates and steel tie plates have a certain constraining effect on the infilled concrete. As the aspect ratio of the grille increases, the bond between the steel faceplates and the inner concrete is weakened, meaning that it cannot effectively limit the out-of-plane deformation of the steel faceplate, weakening the hoop effect.

$$
r_{g}=\frac{B}{h}
$$

where $r_{g}$ is the aspect ratio of the grille, $B$ is the spacing of the steel tie plates, and $h$ is the thickness of the wall, see Figure 10.

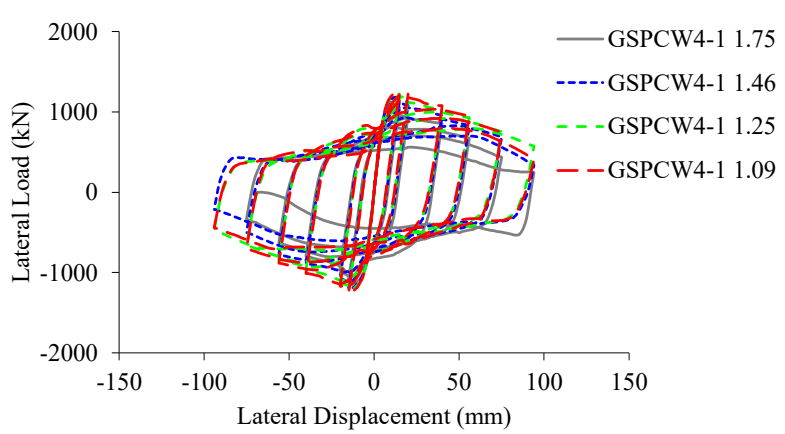

(a)

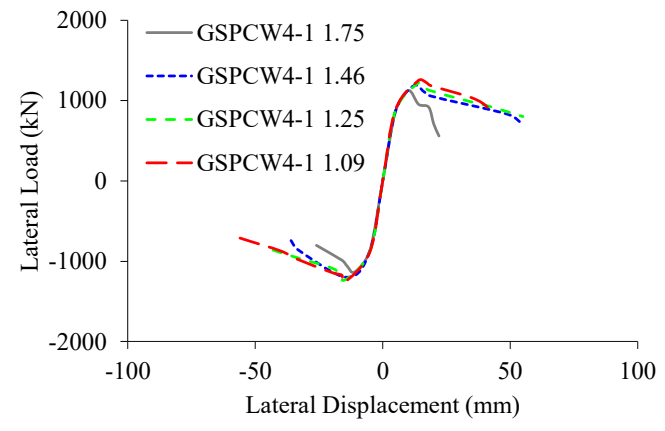

(b)

Figure 9. Influence of the aspect ratio of grille-type steel plate: (a) load-displacement hysteresis curves, and (b) skeleton curves. 


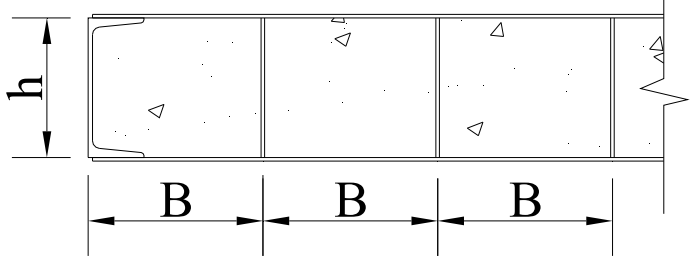

Figure 10. Schematic diagram of the aspect ratio of grille-type steel plate.

\subsection{Concrete Compressive Strength}

The compressive strength of concrete was changed from $30 \mathrm{MPa}$ to $60 \mathrm{MPa}$, and the parametric modeling results are shown in Figure 11. The results show that with increasing concrete strength, the lateral load capacity and stiffness of the test walls increased to a certain degree, but the rate of increase rate was small. Compared with other design variables, the compressive strength of concrete has less influence on the seismic behavior of GSPCW walls.

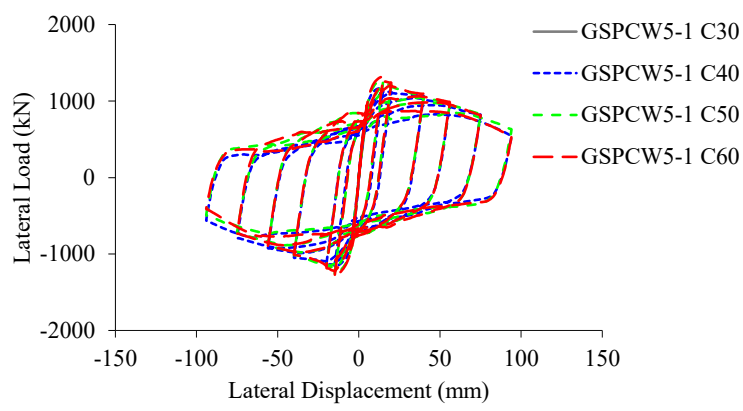

(a)

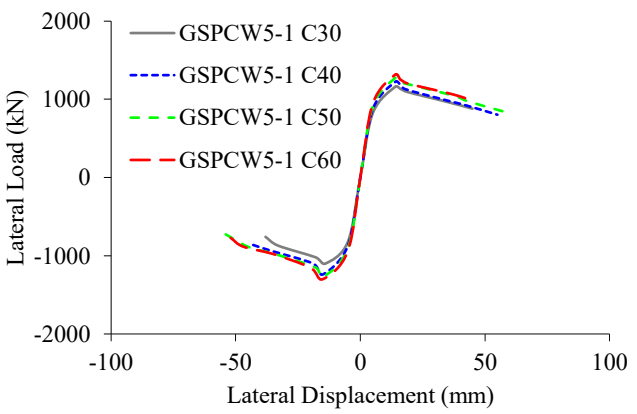

(b)

Figure 11. Influence of concrete compressive strength: (a) load-displacement hysteresis curves, and (b) skeleton curves.

\section{Selection and Modeling of a Case-Study Super-High-Rise Building}

\subsection{Case-Study Building}

To further investigate the potential application of GSPCW walls in real structures, a super-high-rise building was selected for the case study. Figure 12 shows the floor plan of the structure. The structural system of the selected building was a reinforced concrete (RC) frame-core wall system, which is the most commonly used system for super-highrise buildings in China. This system normally combines core walls (in the middle of the plan) and columns (at the perimeter of the plan) to resist later loads, obtaining a balance between lateral resistance and stiffness, along with architectural functions. In this study, the frame columns of the building were concrete-filled steel tube (CFT) columns, and the frame beams were $\mathrm{RC}$ beams and steel beams. The coupling beams of the core walls were steel-concrete coupling beams and RC coupling beams. The floor slabs and roof slab were reinforced concrete slabs, and the thicknesses of the floors were $100 \mathrm{~mm}$ and $120 \mathrm{~mm}$, respectively. Outriggers and mega-braces were used at several stories along the building height to increase the lateral stiffness. The total height of the building was $400 \mathrm{~m}$, with 96 stories. Structural concrete strength was C60 (based on the Chinese design code) for the columns and core walls, and C35 for the floors. The structural steel was Q345, and the reinforcing steel was HRB500 for force-resisting bars and HRB400 for hoops and stirrups. In accordance with the Chinese Code for seismic design of buildings [17], the building was assumed to be on a location representing high seismicity, with a peak ground acceleration (PGA) for the designed earthquake of $0.2 \mathrm{~g}$. The site class was III, and the seismicity group was I, resulting in a characteristic period for the site of $0.45 \mathrm{~s}$. The dead and live loads for both the floor and the roof were $5.0 \mathrm{kN} / \mathrm{m}^{2}$ and $2.0 \mathrm{kN} / \mathrm{m}^{2}$, respectively. The details of 
the design for structural member sizes can be found in Table 4 (horizontal components) and Table 5 (vertical components). It is worth noting that the thickness of the exterior wall in brackets is the thickness for grille-type steel plate concrete composite walls, which is reduced compared to their counterpart RC walls. The steel ratios of the RC walls and GSPCW walls were controlled at $0.8 \%$ and $8 \%$, respectively.

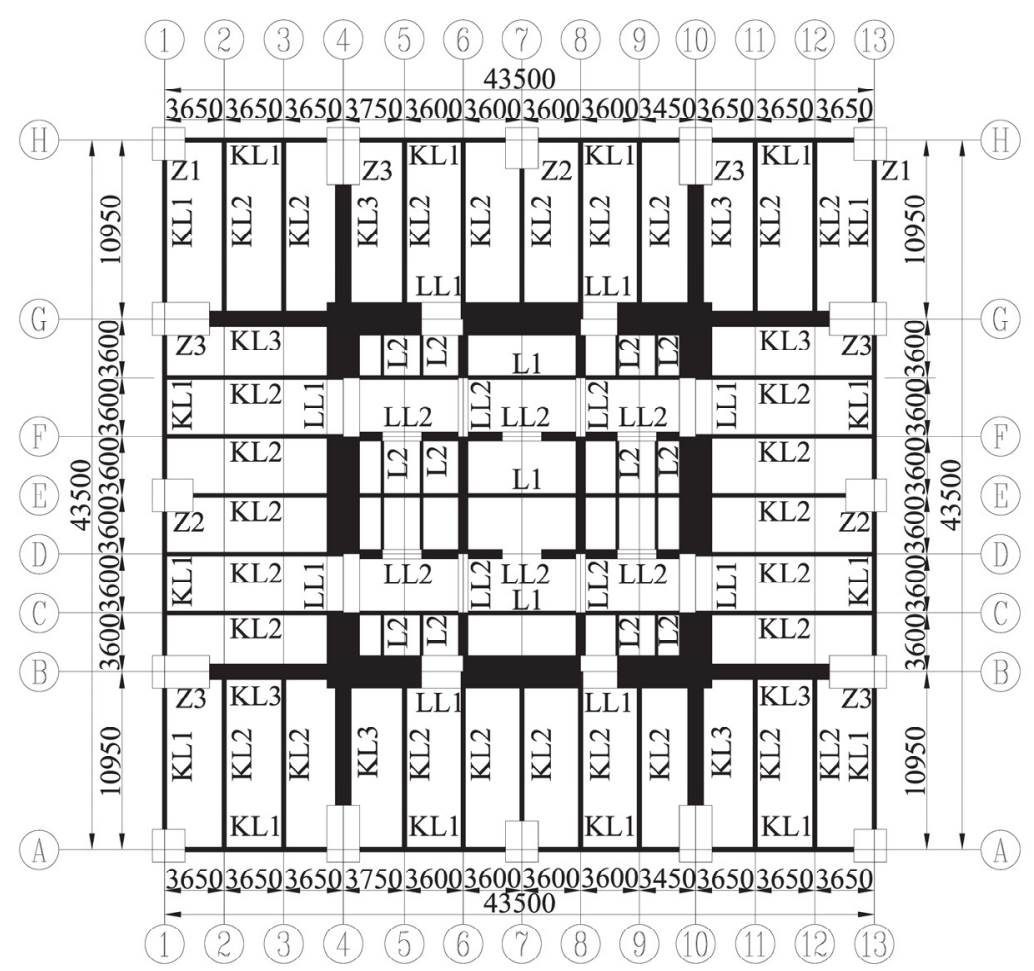

Figure 12. Typical floor plan layout of the case-study building (unit: $\mathrm{mm}$ ).

Table 4. Member size of horizontal components (unit: $\mathrm{mm}$ ).

\begin{tabular}{|c|c|c|c|c|c|c|c|}
\hline Story & KL1 & KL2 & KL3 & LL1 & LL2 & L1 & L2 \\
\hline $1 \sim 4$ & \multirow{10}{*}{$1000 \times 300 \times 28 \times 40$} & \multirow{8}{*}{$900 \times 300 \times 25 \times 40$} & \multirow{7}{*}{$1000 \times 1200$} & $2000 \times 2000+1200 \times 1200 \times 50 \times 50$ & \multirow{2}{*}{$800 \times 1000$} & \multirow{12}{*}{$300 \times 700$} & \multirow{10}{*}{$200 \times 350$} \\
\hline $5 \sim 11$ & & & & \multirow{2}{*}{$1800 \times 2000+1200 \times 1200 \times 50 \times 50$} & & & \\
\hline $12 \sim 14$ & & & & & \multirow{4}{*}{$600 \times 800$} & & \\
\hline $15 \sim 24$ & & & & $1560 \times 1000+800 \times 800 \times 45 \times 45$ & & & \\
\hline $25 \sim 27$ & & & & $1320 \times 1000+800 \times 800 \times 45 \times 45$ & & & \\
\hline $28 \sim 37$ & & & & $1080 \times 1000+800 \times 400 \times 50 \times 55$ & & & \\
\hline $38 \sim 53$ & & & & $1080 \times 1000$ & \multirow{3}{*}{$400 \times 800$} & & \\
\hline $54 \sim 72$ & & & $800 \times 1000$ & $800 \times 1000$ & & & \\
\hline $73 \sim 75$ & & $650 \times 300 \times 14 \times 30$ & & & & & \\
\hline $76 \sim 86$ & & $900 \times 300 \times 25 \times 40$ & & $600 \times 800$ & $300 \times 600$ & & \\
\hline $87 \sim 95$ & \multirow{2}{*}{$700 \times 300 \times 16 \times 30$} & \multirow{2}{*}{\multicolumn{2}{|c|}{$650 \times 300 \times 14 \times 30$}} & \multirow{2}{*}{\multicolumn{2}{|c|}{$300 \times 600$}} & & \\
\hline 96 & & & & & & & $300 \times 700$ \\
\hline
\end{tabular}

Notes: (1) The notation of section size of I-beam is height $\times$ width $\times$ thickness of web $\times$ thickness of flange. (2) The notation of section size of steel reinforcement concrete beam is section size of full section + section size of I-beam. 
Table 5. Member size of vertical components (unit: $\mathrm{mm}$ ).

\begin{tabular}{|c|c|c|c|c|c|c|c|}
\hline Story & $\mathrm{Z1}$ & $\mathbf{Z 2}$ & $\mathbf{Z 3}$ & Inner Wall & Exterior Wall & Truss & Brace \\
\hline $1 \sim 4$ & \multirow{9}{*}{$\begin{array}{c}2000 \times 2000 \times \\
70 \times 70\end{array}$} & \multirow{9}{*}{$\begin{array}{c}2000 \times 3500 \times \\
70 \times 70\end{array}$} & \multirow{9}{*}{$\begin{array}{c}2000 \times 3500 \times \\
70 \times 80\end{array}$} & \multirow{2}{*}{800} & $2000(1350)$ & \multirow{2}{*}{ - } & \multirow{2}{*}{$800 \times 800 \times 55 \times 55$} \\
\hline $5 \sim 11$ & & & & & \multirow{2}{*}{$1800(1350)$} & & \\
\hline $12 \sim 14$ & & & & \multirow{4}{*}{600} & & $700 \times 700 \times 50 \times 50$ & - \\
\hline $15 \sim 24$ & & & & & $1560(1100)$ & - & $1000 \times 1000 \times 60 \times 60$ \\
\hline $25 \sim 27$ & & & & & $1320(1100)$ & $700 \times 700 \times 50 \times 50$ & - \\
\hline $28 \sim 37$ & & & & & \multirow{4}{*}{$1080(-)$} & - & $1000 \times 1000 \times 60 \times 60$ \\
\hline $38 \sim 40$ & & & & \multirow{5}{*}{400} & & $700 \times 700 \times 50 \times 50$ & - \\
\hline $41 \sim 50$ & & & & & & - & $1000 \times 1000 \times 60 \times 60$ \\
\hline $51 \sim 53$ & & & & & & $700 \times 700 \times 50 \times 50$ & - \\
\hline $54 \sim 72$ & $1500 \times 1500$ & $1500 \times 2000$ & $1500 \times 3000$ & & $800(-)$ & - & $1000 \times 1000 \times 60 \times 60$ \\
\hline $73 \sim 75$ & $1200 \times 1200$ & $1200 \times 1600$ & $1200 \times 2000$ & & $600(-)$ & $\begin{array}{l}700 \times 700 \times 50 \times 50 \\
500 \times 500 \times 30 \times 30\end{array}$ & - \\
\hline $76 \sim 86$ & $1000 \times 1000$ & $1000 \times 1200$ & $1000 \times 1800$ & 300 & $600(-)$ & - & $700 \times 700 \times 50 \times 50$ \\
\hline $87 \sim 89$ & \multirow{3}{*}{$500 \times 500$} & \multirow{3}{*}{$500 \times 800$} & \multirow{3}{*}{\multicolumn{2}{|c|}{$650 \times 1000$}} & \multirow{3}{*}{$300(-)$} & $500 \times 500 \times 30 \times 30$ & - \\
\hline $90 \sim 95$ & & & & & & \multirow[t]{2}{*}{ - } & $700 \times 700 \times 50 \times 50$ \\
\hline 96 & & & & & & & - \\
\hline
\end{tabular}

Notes: (1) The notation of section size of CFT column is height $\times$ width $\times$ thickness of steel plate in height direction $\times$ thickness of steel plate in width direction. (2) The rectangular steel tube is used for truss and brace, and the notation of section size is height $\times$ width $\times$ thickness of steel plate in height direction $\times$ thickness of steel plate in width direction. (3) The thickness of exterior wall for GSPCW model is in brackets, and (-) means the walls are not replaced by GSPCW walls.

\subsection{Modeling of the Case-Study Building}

The numerical model of the case-study building was established using the PERFORM3D software [18]. The building core walls were modeled using the General Wall element in PERFORM-3D, considering both the axial-flexural interaction and the nonlinear shear behavior. The axial and flexural behavior of the core walls were modeled using fibersection-based models, while the shear behavior was modeled by defining shear material. The CFT columns were modeled using a fiber section beam-column element in order to consider axial-flexural interaction. For simplicity, all of the beams were modeled using a concentrated plasticity beam-column element, and the constitutive relationship of momentcurvature for the concentrated plastic hinge in the element was determined on the basis of the static elastoplastic method, see Figure 13. For coupling beams, it is critical to include the shear effect to model the shear mechanism of coupling beams. The model adopts rigid floor constraints, where slabs are assumed to be rigid slabs, and all beams have zero axial deformation. All the material models were determined according to current design codes as well as several reference guidelines [15-17,19-21]. Figure 14 shows the elevation view along with the bottom story view of the building model. The core walls of the case-study building were initially designed using RC shear walls, and then the RC walls were substituted with GSPCW walls with reduced wall section sizes. The load combination included 1 times dead load and 0.5 times live load. A comparison of the dynamic characteristics between the RC model and the GSPCW model are provided in Table 6. 


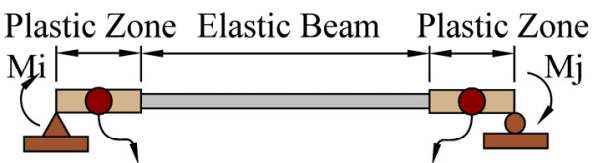

Plastic Hinge Plastic Hinge

(a)

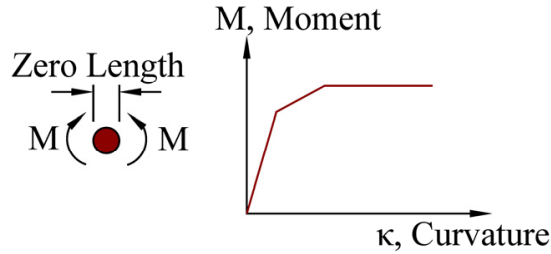

(b)

Figure 13. Plastic hinge beam-column element. (a) Schematic diagram, (b) moment-curvature relationship.

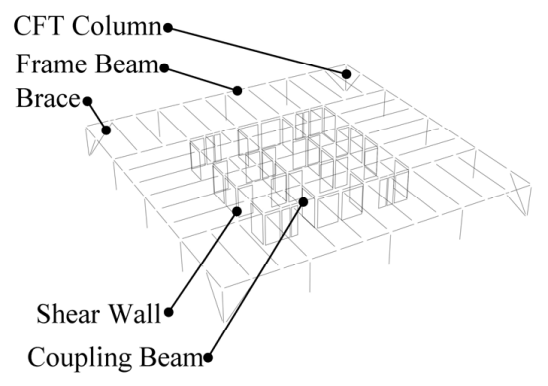

(a)

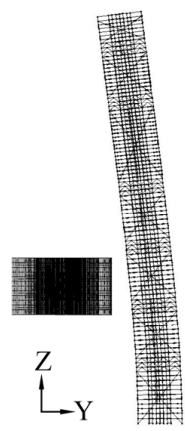

(c)

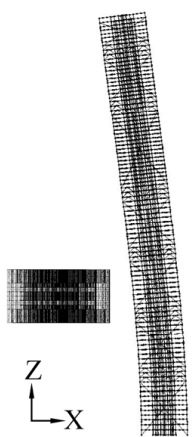

(d)

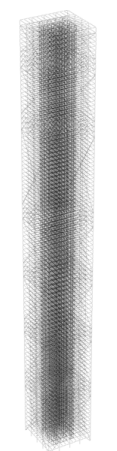

(b)

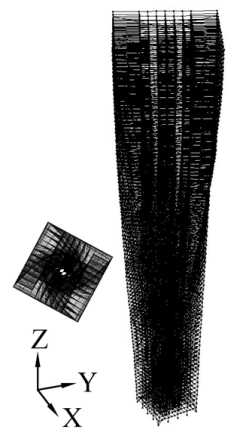

(e)

Figure 14. Schematic of the case-study building model: (a) view of the bottom story; (b) threedimensional view, (c) deformation shape of mode 1, (d) deformation shape of mode 2, (e) deformation shape of mode 3 .

Table 6. Comparison of the dynamic characteristics between the RC and GSPCW building models.

\begin{tabular}{|c|c|c|c|c|c|c|c|c|c|c|}
\hline \multirow{3}{*}{ No. } & \multirow{3}{*}{ Direction } & \multicolumn{4}{|c|}{ RC Model } & \multicolumn{4}{|c|}{ GSPCW Model } & \multirow{3}{*}{$\begin{array}{l}\text { Error of } \\
\text { Periods }\end{array}$} \\
\hline & & \multirow{2}{*}{$\begin{array}{l}\text { Periods } \\
\text { (s) }\end{array}$} & \multirow{2}{*}{$\begin{array}{c}\text { Angle } \\
\text { (deg) }\end{array}$} & \multicolumn{2}{|c|}{ Effective Modal Mass } & \multirow{2}{*}{$\begin{array}{l}\text { Periods } \\
\text { (s) }\end{array}$} & \multirow{2}{*}{$\begin{array}{c}\text { Angle } \\
\text { (deg) }\end{array}$} & \multicolumn{2}{|c|}{ Effective Modal Mass } & \\
\hline & & & & EX & EY & & & EX & EY & \\
\hline 1 & Y & 6.047 & 89.90 & $0.00 \%$ & $56.85 \%$ & 6.117 & 89.84 & $0.00 \%$ & $57.64 \%$ & $1.15 \%$ \\
\hline 2 & $X$ & 5.967 & 179.90 & $56.53 \%$ & $0.00 \%$ & 6.039 & 179.80 & $57.32 \%$ & $0.00 \%$ & $1.20 \%$ \\
\hline 3 & $\mathrm{~T}$ & 2.253 & 90.00 & $0.00 \%$ & $0.00 \%$ & 2.370 & 49.37 & $0.00 \%$ & $0.00 \%$ & $5.19 \%$ \\
\hline 4 & $\mathrm{Y}$ & 1.678 & 89.98 & $0.00 \%$ & $19.87 \%$ & 1.717 & 89.97 & $0.00 \%$ & $20.55 \%$ & $2.33 \%$ \\
\hline 5 & $X$ & 1.612 & 180.00 & $20.33 \%$ & $0.00 \%$ & 1.652 & 180.00 & $20.98 \%$ & $0.00 \%$ & $2.48 \%$ \\
\hline 6 & $\mathrm{~T}$ & 0.883 & 89.27 & $0.00 \%$ & $0.01 \%$ & 0.919 & 86.83 & $0.00 \%$ & $0.00 \%$ & $4.02 \%$ \\
\hline 7 & $\mathrm{Y}$ & 0.875 & 90.01 & $0.00 \%$ & $7.30 \%$ & 0.895 & 90.01 & $0.00 \%$ & $7.35 \%$ & $2.30 \%$ \\
\hline 8 & $X$ & 0.811 & 0.01 & $7.47 \%$ & $0.00 \%$ & 0.831 & 0.01 & $7.52 \%$ & $0.00 \%$ & $2.56 \%$ \\
\hline 9 & Y & 0.592 & 90.00 & $0.00 \%$ & $3.98 \%$ & 0.606 & 90.01 & $0.00 \%$ & $3.88 \%$ & $2.20 \%$ \\
\hline 10 & $\mathrm{~T}$ & 0.542 & 83.24 & $0.00 \%$ & $0.00 \%$ & 0.563 & 85.11 & $0.00 \%$ & $0.00 \%$ & $3.84 \%$ \\
\hline
\end{tabular}




\subsection{Validation of Modeling in PERFORM-3D}

Modeling and validation of GSPCW walls in PERFORM-3D software was performed as follows. First, the elastic modulus of shear walls can be determined on the basis of the modeling manual of PERFORM-3D software [18,22]. Second, modeling of shear behavior of GSPCW walls should include the contribution from both concrete and steel [23], and the shear capacity can be calculated as in [19],

$$
\begin{gathered}
G=p E_{s} \\
\tau=0.27 \sqrt{f_{c}^{\prime}}+\frac{N}{4 A} \\
\tau=0.6 \sqrt{\frac{N}{A}} \\
V_{y k}=\frac{1}{\lambda-0.5}\left(0.4 f_{t k} b h_{0}+0.1 N \frac{A_{w}}{A}\right)+0.8 f_{y v k} \frac{A_{s h}}{s} h_{w 0}+\frac{0.25}{\lambda} f_{a k} A_{a 1}+\frac{0.32}{\lambda} f_{p k} A_{p}
\end{gathered}
$$

On the basis of [24-26], the strain-hardening ratio can be selected as $3 \%$, the shear strain corresponding to the peak shear stress can be determined as 0.0075 , the maximum usable shear strain can be determined as 0.02 , the residual shear capacity can be determined as $40 \%$ of the peak capacity, and the hysteresis degradation coefficient can be selected as 0.3 for all stages. Figure 15 presents a comparison of the numerical modeling results of the two GSPCW test wall specimens using the PERFORM-3D software, as well as a comparison of those results with test data. It can be seen from the figure that the modeling results are reasonably good in terms of bearing load capacity and loading and unloading stiffness. However, the numerical model appears to sustain a larger load capacity for larger lateral displacement compared with the test results. This behavior is likely due to the fact that the modeling assumptions in PERFORM-3D software do not include the consideration of the steel buckling mechanism when the wall reaches a large lateral displacement. This behavior may cause unconservative results for buildings subjected to large earthquake intensities, such as in the near collapse limit state, but should be marginal in the current assessment under this design and the maximum considered earthquake intensity levels.

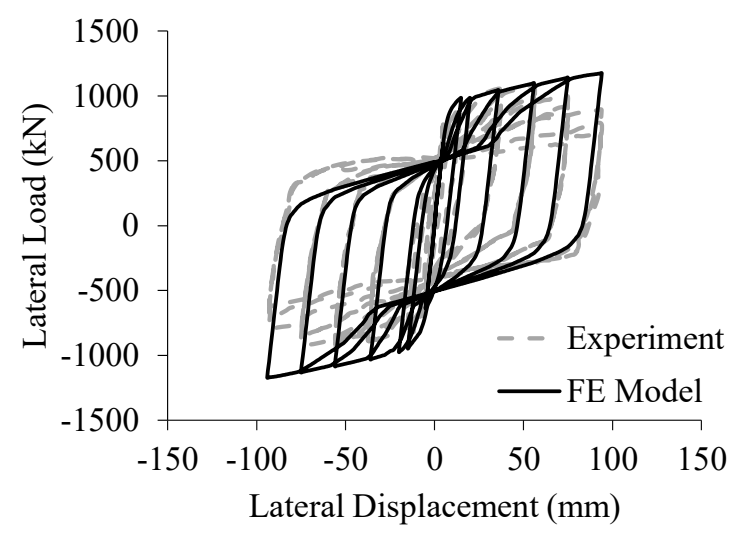

(a)

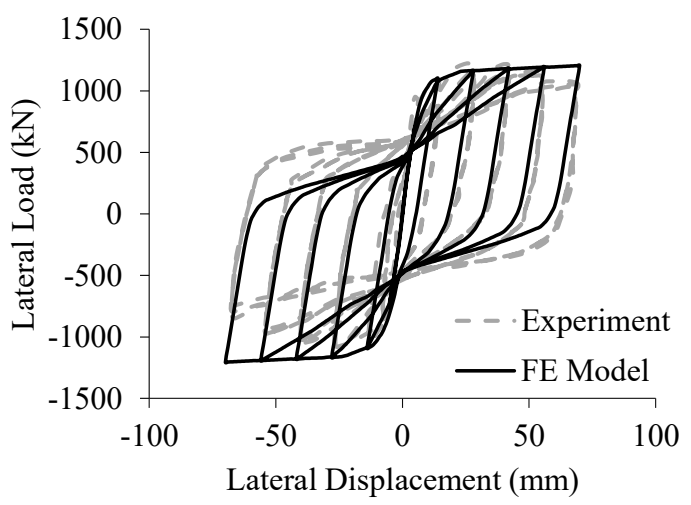

(b)

Figure 15. Validation of PERFORM-3D models in comparison to experimental results: load-displacement hysteresis curves of specimens (a) GSPCW-1 and (b) GSPCW-2.

\section{Seismic Performance Assessment through Nonlinear Time History Analysis}

\subsection{Ground Motions}

For nonlinear time history analysis, a total of ten ground motion records were selected for the current study. The ground motions were selected according to the Chinese Code for the seismic design of buildings [17]. The returning period of the ground motion with 
a $2 \%$ probability of exceedance for design reference periods of 50 years is 2475 years. Each of the ten seismic records was a natural recorded seismic excitation, and the records can be downloaded from the PEER ground motion database. Table 7 presents the basic information for the ten earthquake ground motions, including the earthquake records' site station, year and duration time. The wave forms were scaled according to the site PGA. Figure 16 shows the design spectrum with a 5\% damping ratio based on Chinese Code for seismic design of buildings [17], along with the individual ground motion spectrum. Figure 16 also shows the comparison of the average ground motion spectrum with the design spectrum. It can be inferred from the figure that the average spectrum of the ground motions matches well with the design spectrum in an overall sense.

Table 7. Ground motion information.

\begin{tabular}{cccccc}
\hline No. & Station & Event & Arias Intensity (m/s) & Year & Duration (s) \\
\hline RSN138 & Boshrooyeh & Tabas Iran & 0.3 & 1978 & 35 \\
RSN728 & Westmorland Fire Station & Superstition Hills-02 & 1.2 & 1987 & 60 \\
RSN737 & Agnews State Hospital & Loma Prieta & 0.5 & 1989 & 60 \\
RSN5774 & Nakashinden Town & Iwate Japan & 1.0 & 2008 & 60 \\
RSN5783 & Semine Kurihara City & Iwate Japan & 0.8 & 2008 & 120 \\
RSN5823 & Chihuahua & El Mayor-Cucapah Mexico & 2.3 & 2010 & 130 \\
RSN5829 & RIITO & El Mayor-Cucapah Mexico & 4.7 & 2010 & 130 \\
RSN5977 & Chihuahua & El Mayor-Cucapah Mexico & 0.0 & 2010 & 105 \\
RSN5991 & El Centro Array \#10 & El Mayor-Cucapah Mexico & 3.6 & 2010 & 275 \\
RSN6965 & SBRC & Darfield_New Zealand & 0.7 & 2010 & 64 \\
\hline
\end{tabular}

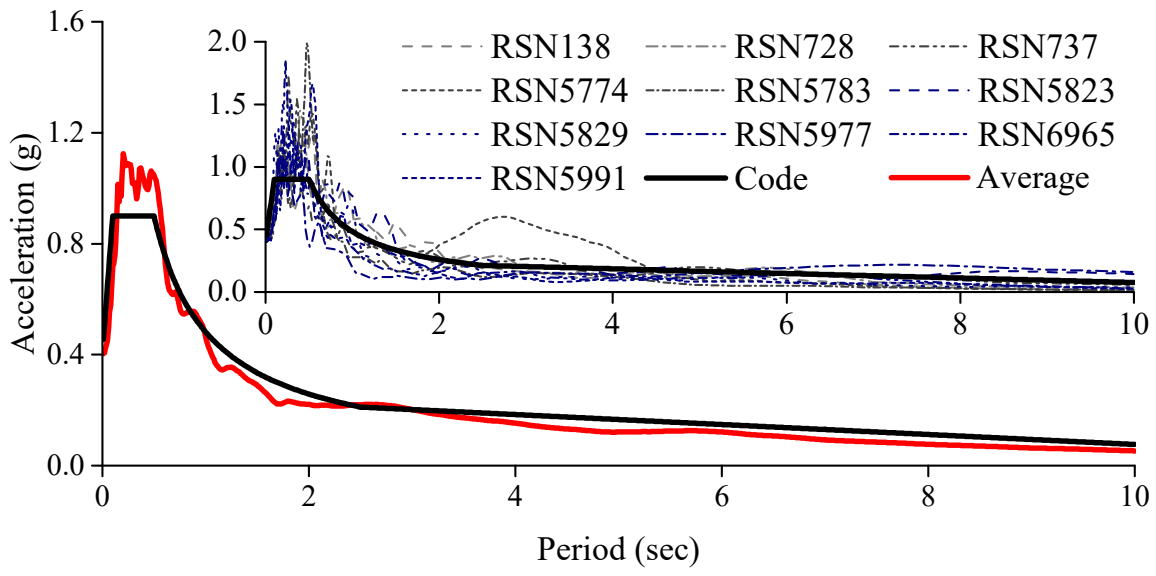

Figure 16. Ground motion data.

\subsection{Story Drifts and Peak Displacements}

The results for story drifts and peak displacements obtained using nonlinear time history analysis (NTHA) are presented in Figure 17 and Figure 18 respectively. In the meantime, the figures compare the results of the GSPCW building and the RC building. It can be seen from the figure that in an overall sense, the GSPCW building model designed with reduced exterior wall section sizes (see Table 5) exhibits similar structural performance as the RC building. The relative errors between the two models are also presented in the figure. Quantitatively, the maximum relative error of story drifts and peak displacements between the two models could reach up to $40 \%$, and the minimum relative error between the two models could be up to $10 \%$. Based on this analysis, the error usually occurs at the bottom of the building. It can be inferred from the results that the GSPCW walls are able to control the story drift response and peak story response to be basically consistent with the RC walls, even if the thickness of the GSPCW walls is reduced by nearly $30 \%$. 


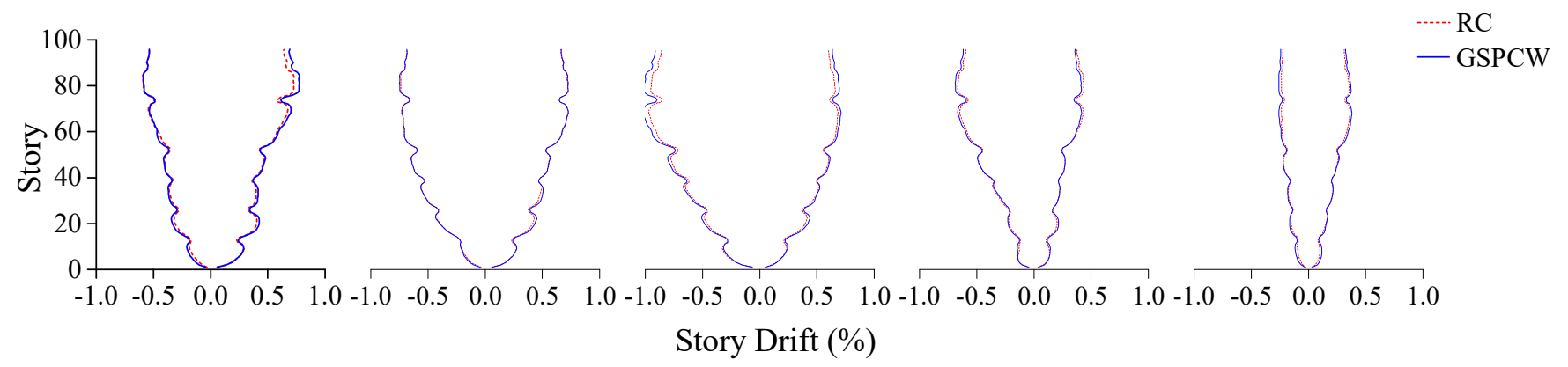

(a)

(b)

(c)

(d)

(e)

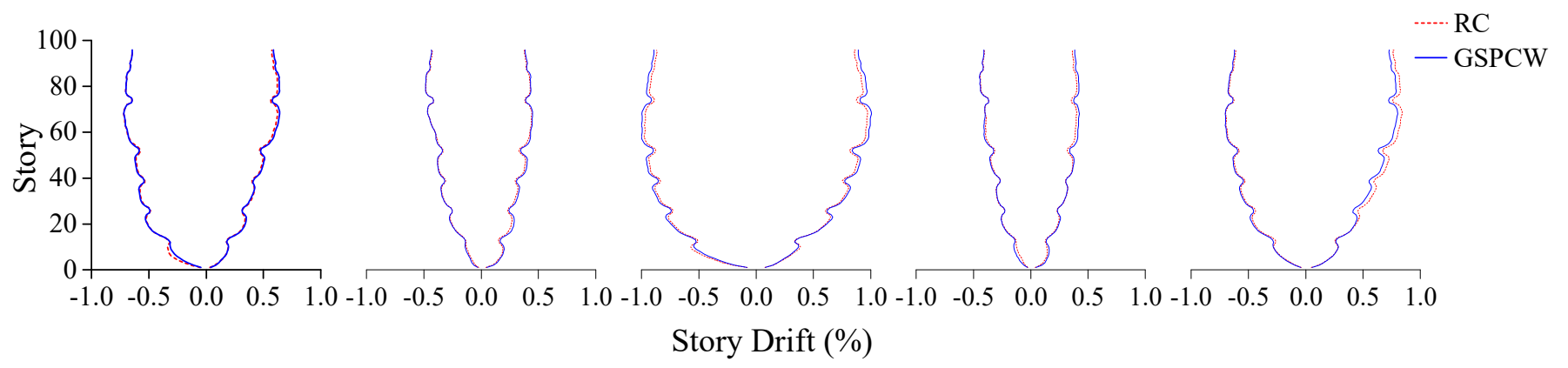

(f)

(g)

(h)

(i)

(j)

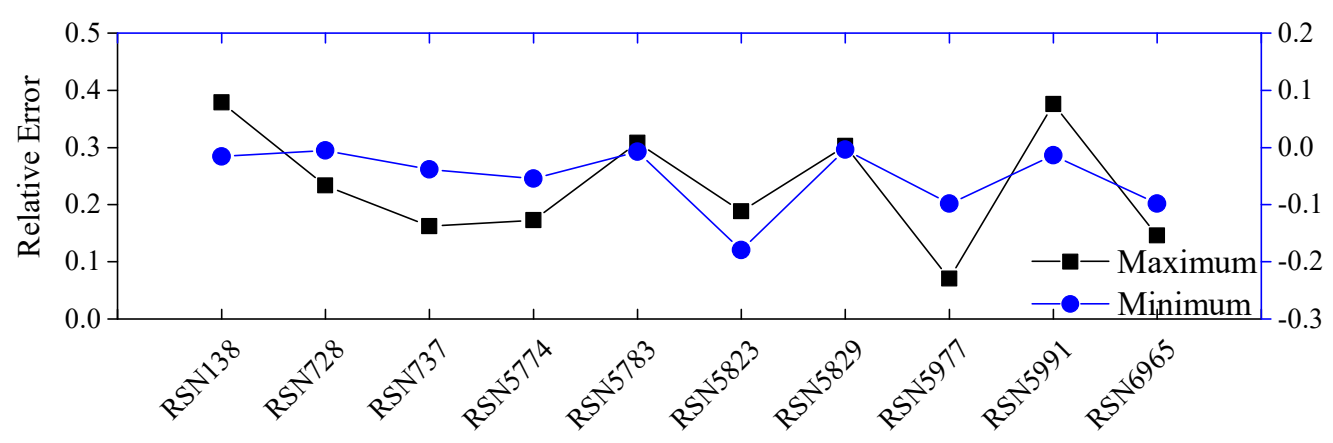

(k)

Figure 17. Comparison of story drift ratios of each ground motion between RC and GSPCW models: (a) RSN138; (b) RSN728; (c) RSN737; (d) RSN5774; (e) RSN5783; (f) RSN5823; (g) RSN5829; (h) RSN5977; (i) RSN5991; (j) RSN6965; (k) Relative error.

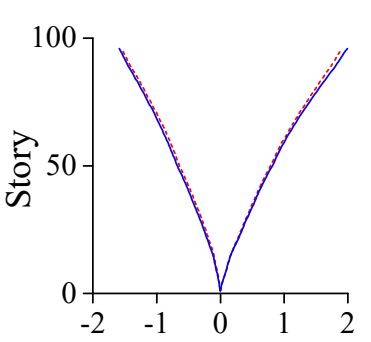

(a)

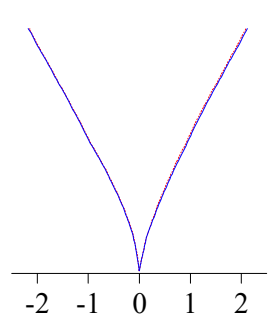

(b)

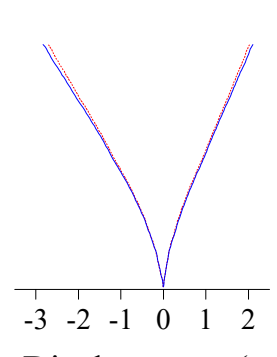

Displacement (m)
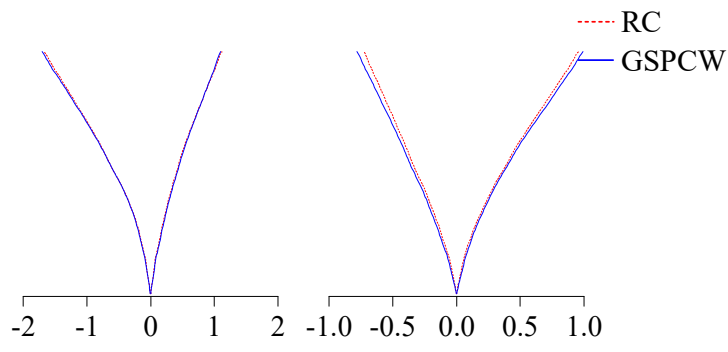

(c)

(d)

(e)

Figure 18. Cont. 


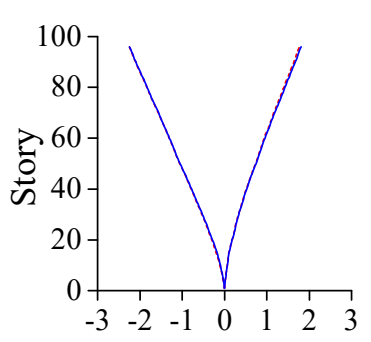

(f)

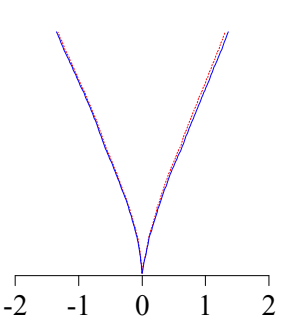

(g)
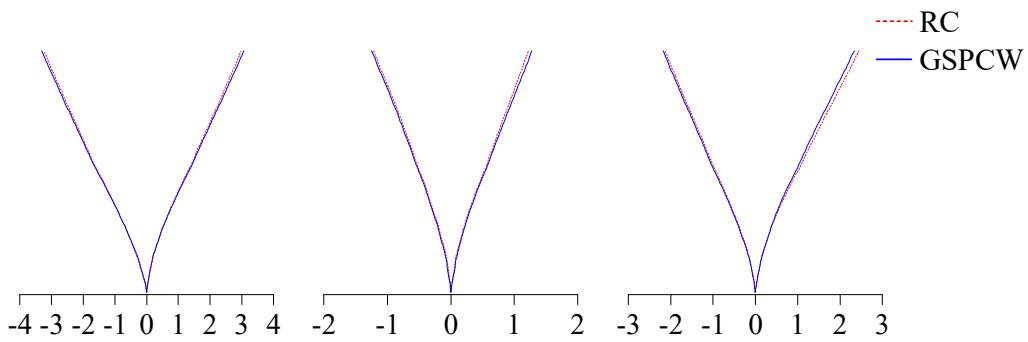

Displacement (m) (i)

(j)

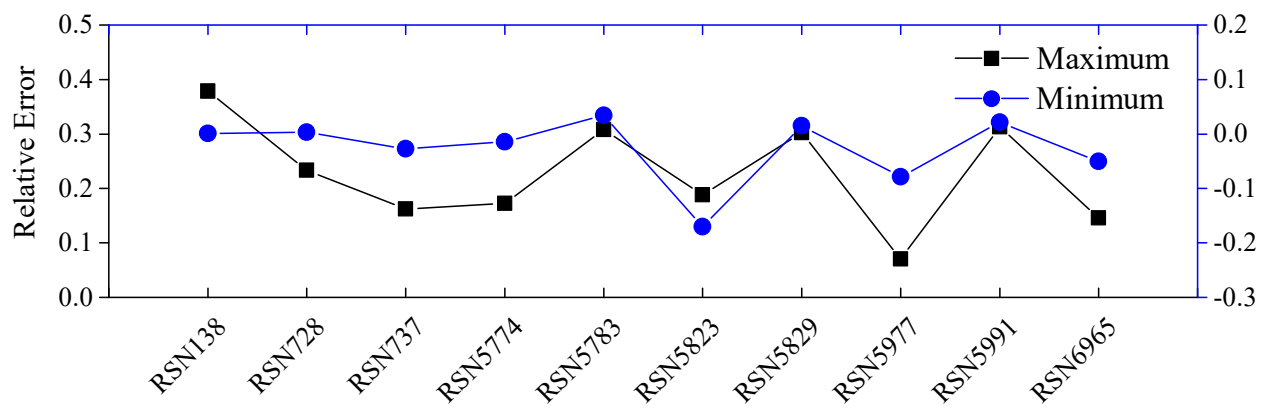

(k)

Figure 18. Comparison of story displacement of each ground motion between RC and GSPCW models: (a) RSN138; (b) RSN728; (c) RSN737; (d) RSN5774; (e) RSN5783; (f) RSN5823; (g) RSN5829; (h) RSN5977; (i) RSN5991; (j) RSN6965; (k) Relative error.

\subsection{Story Shear Forces and Overturning Moments}

Similarly, Figures 19 and 20 show the results of story shear forces and story moments of the two building models obtained using NTHA. It can be clearly seen from these figures that the story shear force and the story moment responses at the bottom of the GSPCW building are generally higher than those of the RC building, which is due to the greater stiffness and higher capacity of the GSPCW walls.

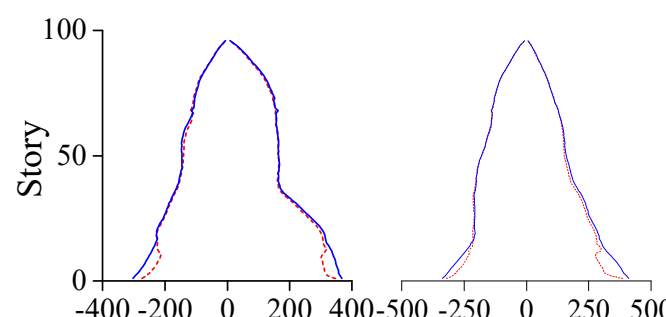

$\begin{array}{lllllllll}-400 & -200 & 0 & 200 & 400-500 & -250 & 0 & 250 & 500\end{array}$

(a) (b)
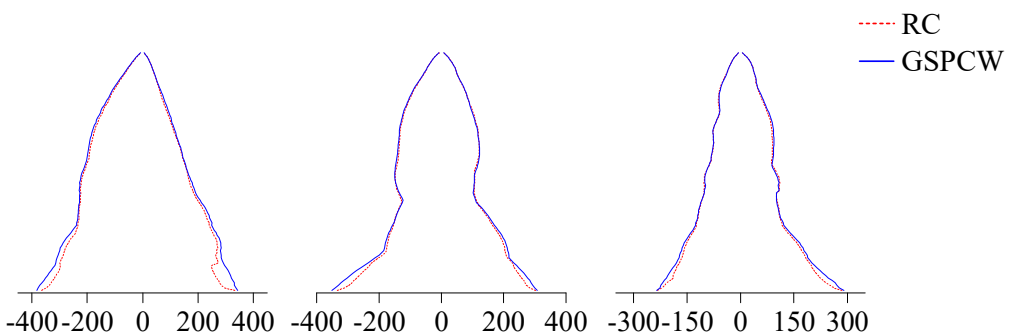

Shear Force (MN)

(c)

(d)

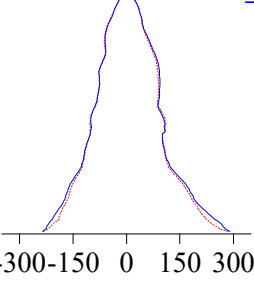

(e)

Figure 19. Cont. 


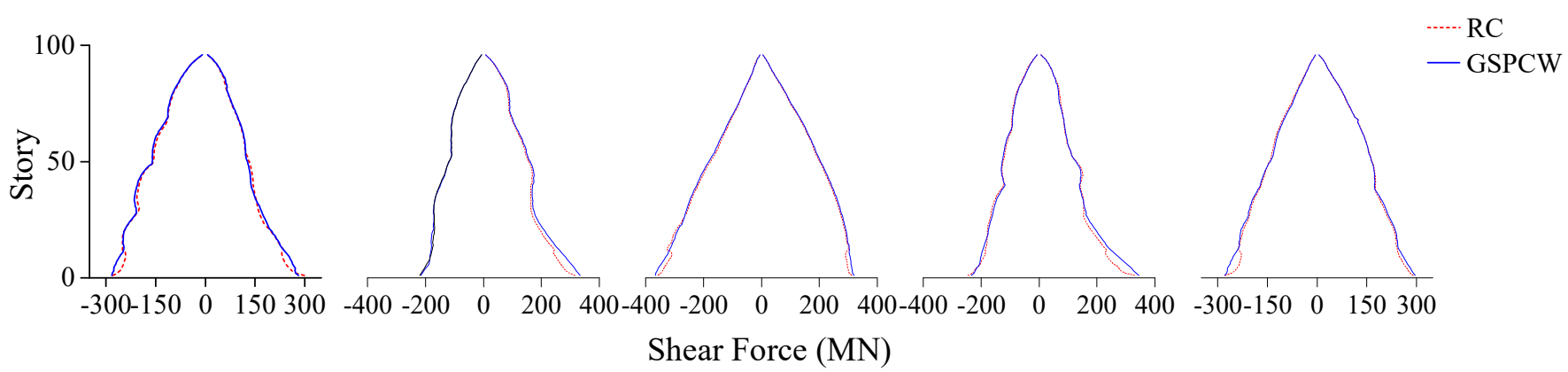

$(\mathbf{f})$

$(\mathrm{g})$

(h)

(i)

(j)

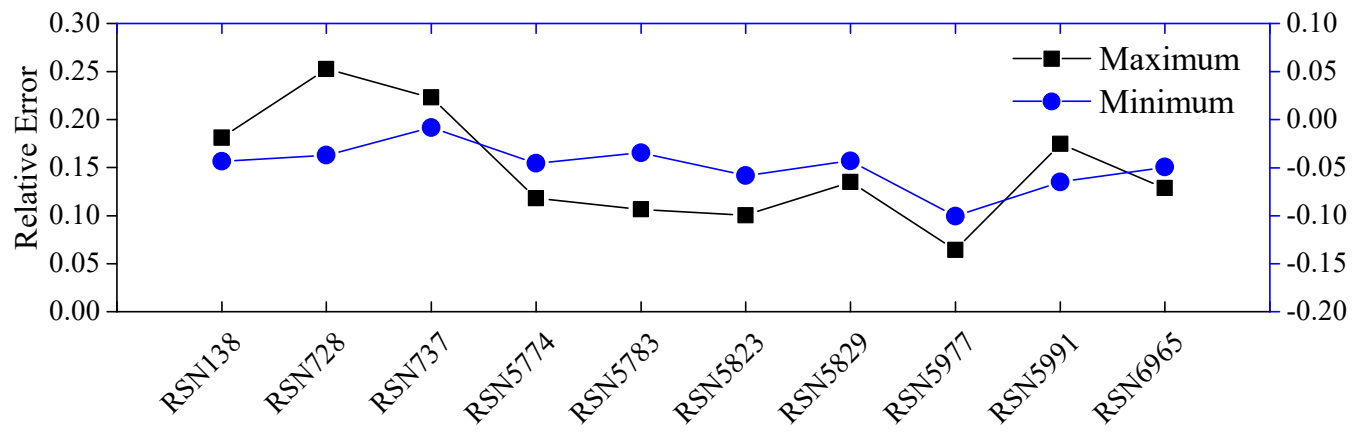

(k)

Figure 19. Comparison of story shear forces of each ground motion between RC and GSPCW models: (a) RSN138; (b) RSN728; (c) RSN737; (d) RSN5774; (e) RSN5783; (f) RSN5823; (g) RSN5829; (h) RSN5977; (i) RSN5991; (j) RSN6965; (k) Relative error.

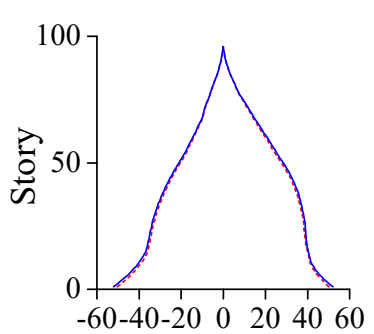

(a)

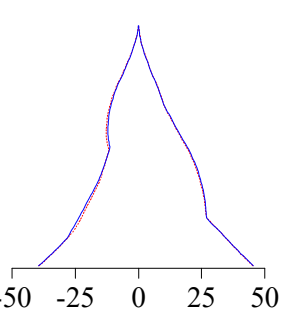

(b)

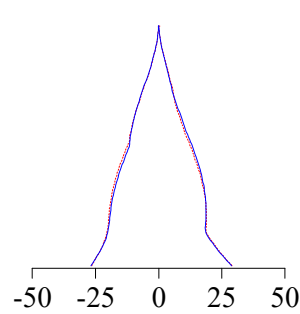

Moment $(\mathrm{MN} * \mathrm{~m})$

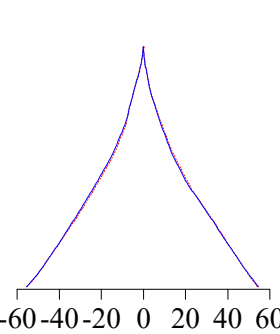

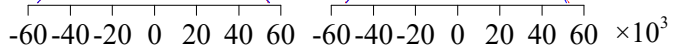

$\cdots \cdot \mathrm{RC}$

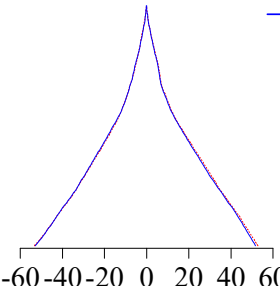

- GSPCW

(c)

(d)

(e)

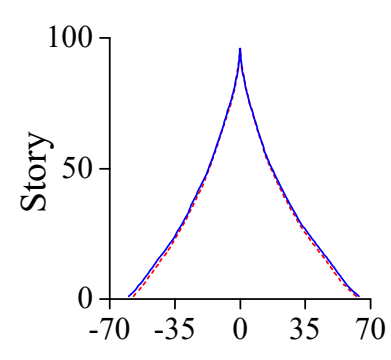

(f)

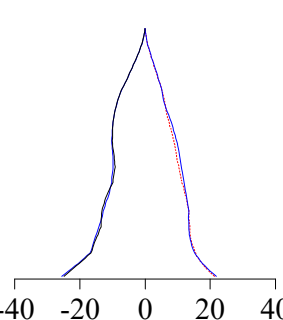

(g)

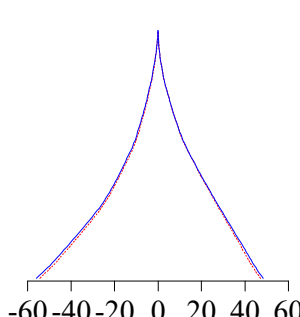

$-60-40-20 \begin{array}{lllllllll} & 20 & 40 & 60 & -60-40-20 & 0 & 20 & 40 & 60\end{array}$

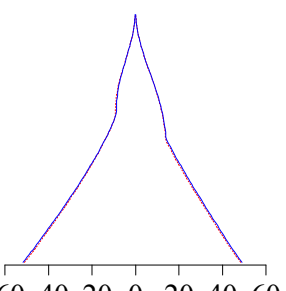

Moment $(\mathrm{MN} * \mathrm{~m})$

(h)

(i)

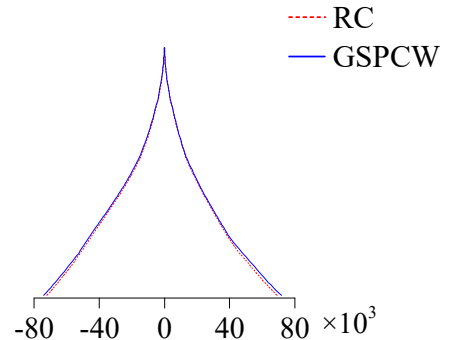

(j)

Figure 20. Cont. 


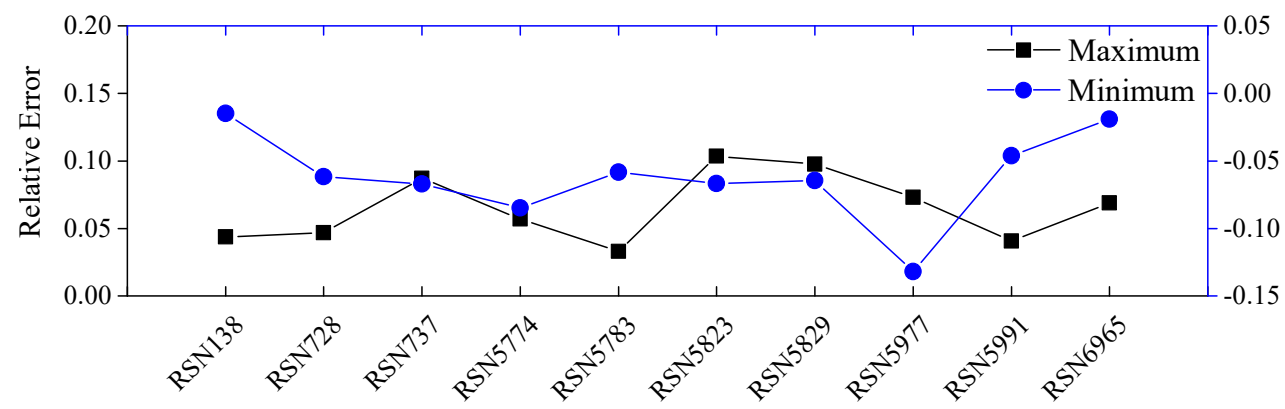

$(\mathbf{k})$

Figure 20. Comparison of story moments of each ground motion between RC and GSPCW models: (a) RSN138; (b) RSN728; (c) RSN737; (d) RSN5774; (e) RSN5783; (f) RSN5823; (g) RSN5829; (h) RSN5977; (i) RSN5991; (j) RSN6965; (k) Relative error.

\section{Seismic Performance Assessment through Modal Pushover Analysis}

\subsection{Story Drifts and Peak Displacements}

Figure 21 shows the story drift response and peak story response of the RC building model and the GSPCW building model along the building height obtained using both Model Pushover Analysis (MPA) and the average NTHA results. The MPA procedure analyzes structures using pushover analysis at several selected modes, and combines the modal responses using a certain combination rule to obtain the final response. Since this procedure is able to include higher mode responses, it is becoming more popular than conventional pushover analysis for the seismic performance assessment of high-rise buildings. In this study, the first five modes of the case-study building were selected for MPA analysis. Details of the theory and procedure for MPA are not addressed in this paper for simplicity.

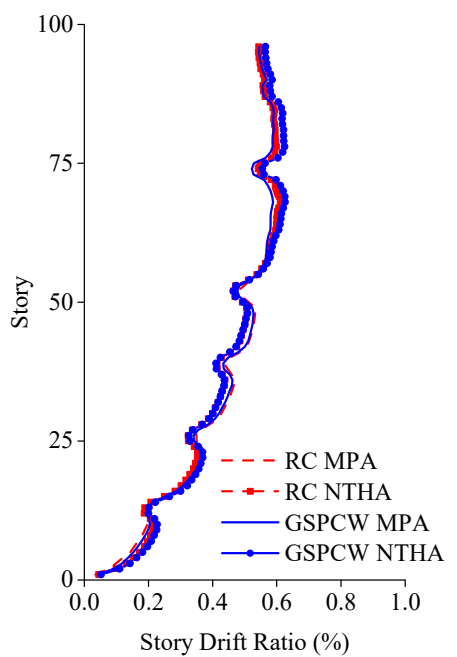

(a)

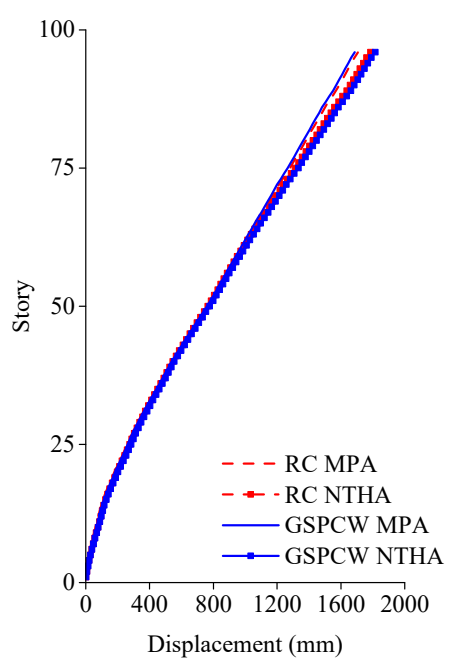

(b)

Figure 21. Comparison of story deformation between the RC and GSPCW models: (a) story drift ratios; (b) peak story displacements.

From the comparison between the MPA and NTHA results, it can be confirmed that the structural response calculated on the basis of MPA with five modes was in very good agreements with the results obtained from NTHA, especially for stories below 60 . Comparing the RC building model and the GSPCW building model, it can be found that the deformation response between the two models is almost identical, and the requirements in the specification are satisfied no matter which method is used. 


\subsection{Story Shear Forces and Overturning Moments}

Figure 22 shows the story shear force and story moment results from MPA and compares the results from the average NTHA analysis. Similar to the response of the previous section, both the MPA results for story shear force and the story moments for the GSPCW and RC building models are in good agreement with the NTHA results, and the difference in the story force responses between the GSPCW and RC building models is also small.

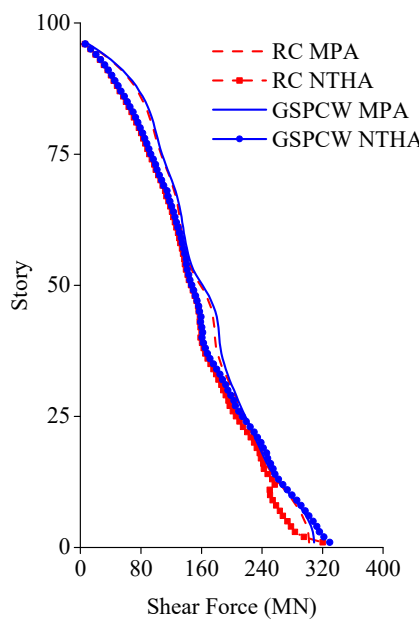

(a)

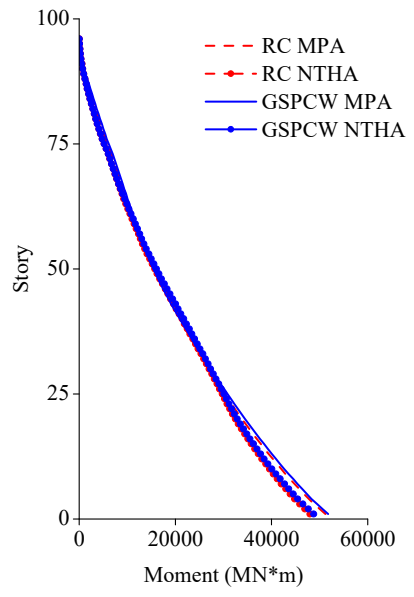

(b)

Figure 22. Comparison of story force between the RC and GSPCW models: (a) story shear forces; (b) story overturning moments.

These results from MPA verify that using five modal responses is enough to accurately determine the nonlinear response in the current study. However, the time consumed for MPA is much less than that required for NTHA, which definitely broadens the use of MPA in the analysis of super-high-rise buildings.

\section{Economic Assessment}

To further assess the economic performance of GSPCW walls, a simple economic evaluation of GSPCW for application in the selected super-high-rise building was performed. Note that this assessment was for the whole structure, including both the original structure and the parts of structure where the conventional RC core walls were replaced with GSPCW walls. Figure 23 and Table 8 present the results from this simple economic assessment. In the RC model and the GSPCW model, the proportions of concrete were $74.78 \%$ and $73.14 \%$, respectively, while the proportions of steel were $25.22 \%$ and $26.86 \%$, respectively. According to the statistical results, in terms of the GSPCW model versus the RC model, the amount of concrete was reduced by $1.64 \%$, while the amount of steel was increased by $1.64 \%$. In this regard, it can be seen that the overall increase in steel use was marginal when using GSPCW walls in the lower $1 / 3$ of the building. Table 8 lists the material construction prices for each model (considering concrete to be $1100 \mathrm{JPY} /$ ton and steel to be $12,000 \mathrm{JPY} /$ ton). It shows that the material price for the GSPCW models is only increased by about $2.2 \%$ per unit area. However, due to the reduction in GSPCW wall thickness, the available architecture area of the GSPCW building increases by $1283.9 \mathrm{~m}^{2}$, which is almost a $3 \%$ increment over the original area. Therefore, the economy of GSPCW walls can still be considered to be reasonable. 


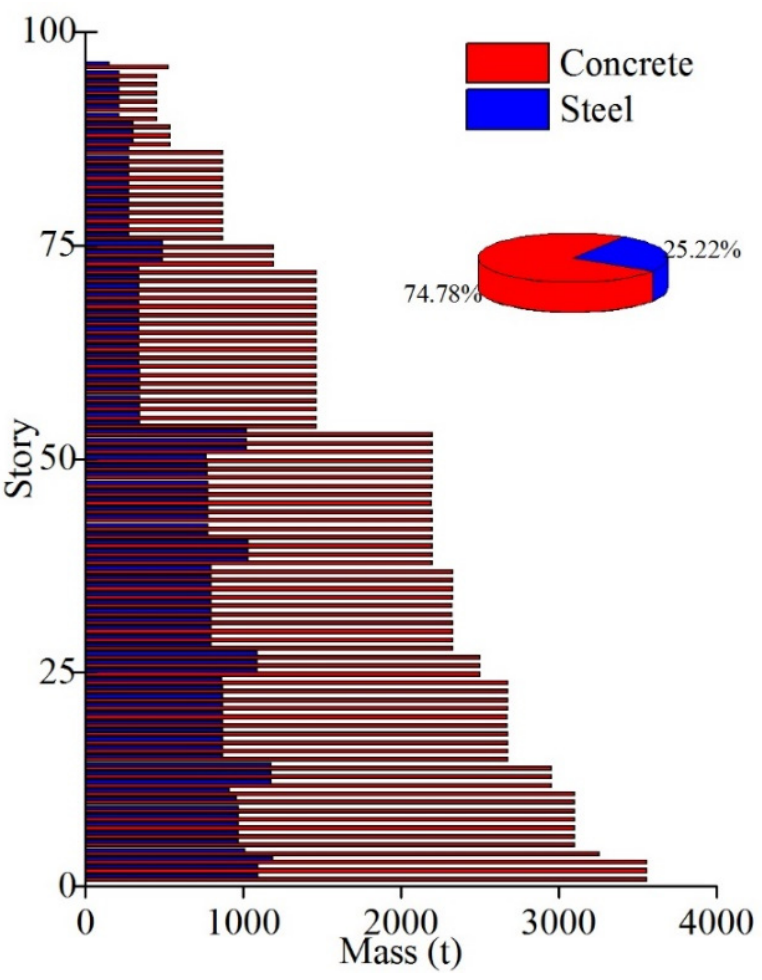

(a)

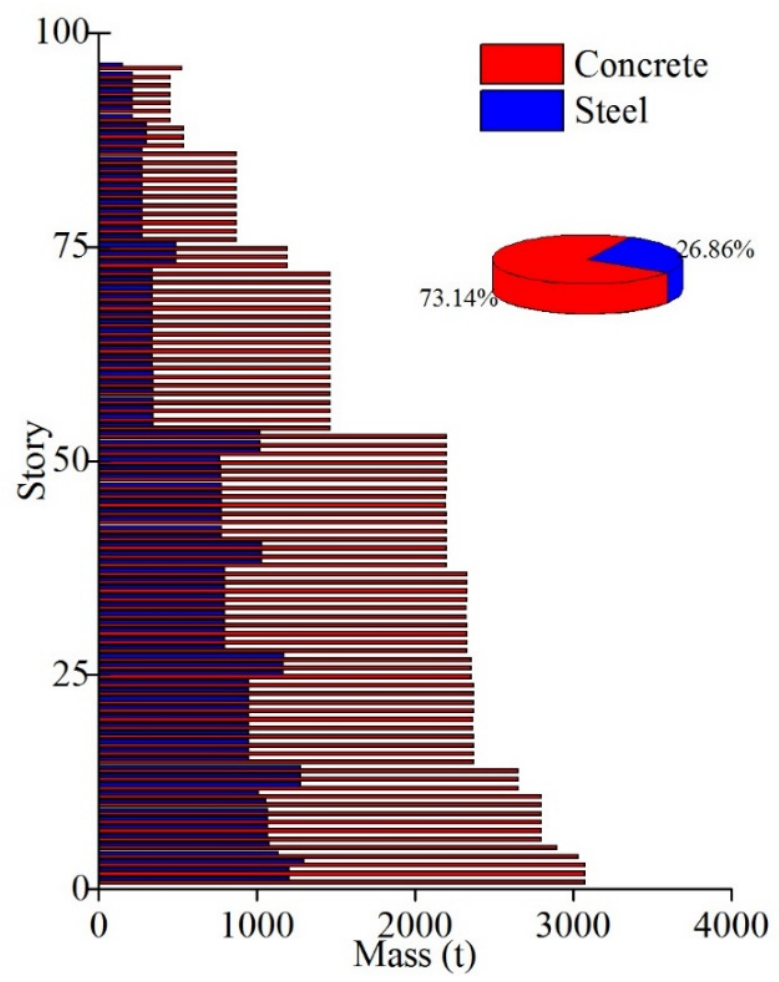

(b)

Figure 23. Comparison of material consumption: (a) RC models; (b) GSPCW models.

Table 8. Statistics of material mass and available area.

\begin{tabular}{cccccccccc}
\hline & \multicolumn{4}{c}{ RC Model } & & \multicolumn{2}{c}{ GSPCW Model } \\
\cline { 2 - 9 } & $\begin{array}{c}\text { Total } \\
\text { Area }\left(\mathbf{m}^{2}\right)\end{array}$ & $\begin{array}{c}\text { Mass of } \\
\text { Concrete } \\
(\mathbf{t})\end{array}$ & $\begin{array}{c}\text { Mass of } \\
\text { Steel }(\mathbf{t})\end{array}$ & $\begin{array}{c}\text { Price } \\
\left(\mathbf{J P Y} / \mathbf{m}^{2}\right)\end{array}$ & $\begin{array}{c}\text { Available } \\
\text { Area }\left(\mathbf{m}^{2}\right)\end{array}$ & $\begin{array}{c}\text { Mass of } \\
\text { Concrete } \\
(\mathbf{t})\end{array}$ & $\begin{array}{c}\text { Mass of } \\
\text { Steel }(\mathbf{t})\end{array}$ & $\begin{array}{c}\text { Price } \\
\left(\mathbf{J P Y} / \mathbf{m}^{2}\right)\end{array}$ & $\begin{array}{c}\text { Available } \\
\text { Area }\left(\mathbf{m}^{2}\right)\end{array}$ \\
\hline Total & $181,660.8$ & $182,892.7$ & $61,696.3$ & 5182.9 & $45,754.7$ & $174,796.8$ & $64,181.8$ & 5298.1 & $47,038.6$ \\
\hline
\end{tabular}

\section{Conclusions}

This paper investigated the seismic performance of GSPCW walls from the component level to the structural level, performing (1) numerical and parametric analysis of GSPCW walls using FEM DIANA software, (2) nonlinear analysis of a super-high-rise building as a case study with the application of GSPCW walls through the NTHA and MPA procedure. The following key findings can be drawn from the study.

1. Parametric analysis results show that the steel ratio has a critical effect on the load capacity and stiffness of GSPCW walls, since steel plate is the only source of steel in GSPCW walls, and no additional reinforcement (e.g., reinforcing bars) is used. The height-to-width ratio has a critical influence on the failure mode of GSPCW walls. The axial load ratio has some influence on the ductility of GSPCW walls, i.e., the ductility decreases as the axial load ratio increases, which is especially evident when the axial load ratio is greater than 0.5. Based on the current study, it is suggested that the axial load ratio be kept below 0.5 in practice in order to maintain good ductility. The aspect ratio of the grille determines the constraining effect from the steel plate on the filled concrete, which should be considered during the design process. Concrete compressive strength has little to no effect on the seismic performance of GSPCW.

2. After replacing the ordinary reinforced concrete shear walls with GSPCW walls with wall thickness reduced by $30 \%$, the GSPCW building was still able to control the 
overall deformation of the structures to a good extent, and the average deformation response from the analyses met the code requirements.

3. In this study, the MPA procedure using five modes was verified to be accurate enough to provide similar results to those obtained using the NTHA procedure for nonlinear analysis. However, the time required for MPA analysis is much less than that required for NTHA.

4. Based on a simple statistical analysis of the current case study, the amount of concrete consumed for the whole structure was decreased by $1.64 \%$ using the GSPCW model, while the steel consumption increased by $1.64 \%$, which shows a marginal overall increase in steel consumption using GSPCW walls. Economic analysis shows the cost of materials for GSPCW models was only increased by about 2.2\% per unit area. However, due to the reduction in the thickness of GSPCW walls, the available architecture area of GSPCW buildings is increased by almost 3\% compared to the original area. Therefore, the economy of GSPCW walls can still be considered reasonable.

Author Contributions: Conceptualization, Y.L. (Yang Liu); Funding acquisition, H.W.; Investigation, H.W. and Q.Y.; Project administration, Y.L. (Yun Li); Resources, J.L.; Writing—original draft, H.W. and Q.Y.; Writing-review \& editing, H.W. and L.L. All authors have read and agreed to the published version of the manuscript.

Funding: This research was funded by China Construction Seventh Engineering Division Corp., Ltd., grant number cscec7b-2019-Z-22.

Institutional Review Board Statement: Not applicable.

Informed Consent Statement: Not applicable.

Acknowledgments: This work was financially supported by a grant from the Science Research Development Program of China Construction Seventh Engineering Division Corp., Ltd. (Grant No. cscec7b-2019-Z-22), which is gratefully acknowledged by the authors. The authors also want to acknowledge professor Wenping Xu from Southeast University of China for his previous test work on GSPCW system, which makes the analytical work of this study possible.

Conflicts of Interest: The authors declare no conflict of interest.

\section{References}

1. Nie, J.G.; Tao, M.X.; Fan, J.S.; Pu, F.M.; Hu, H.S.; Ma, X.W.; Li, S.Y.; Liu, F.J. Research advances of composite shear walls with double steel plates and filled concrete. J. Build. Struct. 2011, 41, 52-60. (In Chinese)

2. Wang, W.; Wang, Y.; Lu, Z. Experimental study on seismic behavior of steel plate reinforced concrete composite shear wall. Eng. Struct. 2018, 160, 281-292. [CrossRef]

3. Ozaki, M.; Akita, S.; Osuga, H.; Nakayama, T.; Adachi, N. Study on steel plate reinforced concrete panels subjected to cyclic in-plane shear. Nucl. Eng. Des. 2004, 228, 225-244. [CrossRef]

4. Emori, K. Compressive and shear strength of concrete filled steel box wall. Int. J. Steel Struct. 2002, 2, 29-40.

5. Link, R.A.; Elwi, A.E. Composite concrete-steel plate walls: Analysis and behavior. J. Struct. Eng. 1995, 121, 260-271. [CrossRef]

6. $\mathrm{Xu}, \mathrm{W} . \mathrm{P}$; $\mathrm{Xu}, \mathrm{T}$. Seismic performance test of grille type double steel plate concrete composite shear wall. J. Archit. Civ. Eng. 2018, 35, 111-118. (In Chinese)

7. Guo, X. Study on Seismic Behavior of Grid-Type Steel Tube-Concrete Composite Shear Walls. Master's Thesis, Southeast University, Nanjing, China, 2016. (In Chinese).

8. $\mathrm{Xu}, \mathrm{T}$. Experimental Study on Grille-Type Steel Plate Concrete Composite Shear Wall under Low Cyclic Loading. Master's Thesis, Southeast University, Nanjing, China, 2017. (In Chinese).

9. Ye, S. Study on Seismic Performance of Concrete Filled Steel Tube Frame-Grille Type Steel Plate Shear Wall Structure. Master's Thesis, Southeast University, Nanjing, China, 2018. (In Chinese).

10. Zhang, X.L.; Liu, Y.; Wang, T.; Xu, W.P. Anti-seismic test study on the grid-tube-type double steel plate and infilled concrete composite shear wall. IOP Conf. Ser. Earth Environ. Sci. 2021, 719, 022004. [CrossRef]

11. DIANA. User's Manual_DIANA Documentation Release 10.3; Version 10.3; DIANA FEA BV.: Delft, The Netherlands, 2019.

12. Mander, J.B.; Prestley, M.J.; Park, R. Theoretical stress-strain model for confined concrete. Am. Soc. Civ. Eng. 1988, 114, 1804-1826. [CrossRef]

13. Cai, J.; Sun, G. Constitutive relationship of concrete core confined by square steel tube. J. South China Univ. Technol. 2008, 36, 105-109. 
14. CEB-FIP Model 1990. In Model Code for Concrete Structures (1990): Chapter 2: Material Properties; International Federation for Structural Concrete: Lausanne, Switzerland, 1991.

15. GB 50010-2010. In Code for Design of Concrete Structures; China Architecture \& Building Press: Beijing, China, 2015. (In Chinese)

16. GB 50017-2017. In Standard for Design of Steel Structures; China Architecture \& Building Press: Beijing, China, 2017. (In Chinese)

17. GB 50011-2010. In Code for Seismic Design of Buildings; China Architecture \& Building Press: Beijing, China, 2016. (In Chinese)

18. PERFORM-3D. In User Guide PERFORM-3DTM Nonlinear Analysis and Performance Assessment for 3D Structures; Version 7; Computers and Structures, Inc.: Berkeley, CA, USA, 2018.

19. JGJ 138-2016. In Code for Design of Composite Structures; China Architecture \& Building Press: Beijing, China, 2016. (In Chinese)

20. JGJ 3-2010. In Technical Specification for Concrete Structures of Tall Building; China Architecture \& Building Press: Beijing, China, 2010. (In Chinese)

21. GB 50009-2012. In Load Code for the Design of Building Structures; China Architecture \& Building Press: Beijing, China, 2012. (In Chinese)

22. PERFORM-3D. In Components and Elements for PERFORM-3DTM; Version 7; Computers and Structures, Inc.: Berkeley, CA, USA, 2018

23. Zhang, C.Q. Study on the Key Issues of Seismic Performance of Super High-Rise Structures with New Type Energy Dissipation Outrigger Truss. Ph.D. Thesis, Tongji University, Shanghai, China, 2014. (In Chinese)

24. FEMA 273. In NEHRP Guidelines for the Seismic Rehabilitation of Buildings; Federal Emergency Management Agency: Washington, DC, USA, 1997.

25. FEMA 356. In Prestandard and Commentary for the Seismic Rehabilitation of Building; Federal Emergency Management Agency: Washington, DC, USA, 2000.

26. Elwood, K.J.; Matamoros, A.B.; Wallace, J.W.; Lehman, D.E.; Heintz, J.A.; Mitchell, A.D.; Moore, M.A.; Valley, M.T.; Lowes, L.N.; Comartin, C.D.; et al. Update to ASCE/SEI 41 concrete provision. Earthq. Spectra 2007, 23, 493-523. [CrossRef] 